Research Article

\title{
Sodium Periodate as a Selective Oxidant for Diclofenac Sodium in Alkaline Medium: A Quantum Chemical Approach
}

\author{
Madhu Gupta $^{1 *}$, Amrita Srivastava ${ }^{1}$, Sheila Srivastava ${ }^{2}$ \\ ${ }^{1}$ Department of Chemistry, University of Lucknow, Lucknow, Uttar Pradesh, India. \\ ${ }^{2}$ Chemical Laboratories, Feroze Gandhi College, Raebareli, Uttar Pradesh, India.
}

Received: $15^{\text {th }}$ April 2020; Revised: $4^{\text {th }}$ July 2020; Accepted: $6^{\text {th }}$ July 2020; Available online: 30th July 2020; Published regularly: August 2020

\begin{abstract}
Diclofenac sodium is a well known anti-inflammatory drug. It has also been proclaimed to exhibit adverse effects on aquatic animals through sewage and waste water treatment plants. Kinetic and mechanistic studies of the novel oxidation of diclofenac sodium (DFS) by sodium periodate were discussed with an emphasis on structure and reactivity by using kinetic and computational approach. The proposed work had been studied in alkaline medium at $303 \mathrm{~K}$ and at a constant ionic strength of 0.60 mol. $\mathrm{dm}^{-3}$. Formation of [2-(2,6-dicloro-phynylamino)-phenyl]-methanol as the oxidation product of DFS is confirmed with the help of structure elucidation. The active species of catalyst, oxidant and oxidation products were recognized by UV and IR spectral studies. Proton inventory studies in $\mathrm{H}_{2} \mathrm{O}-\mathrm{D}_{2} \mathrm{O}$ mixtures had been shown the involvement of a single exchangeable proton of $\mathrm{OH}^{-}$ion in the transition state. All quantum chemical calculations were executed at level of density functional theory (DFT) with B3LYP function using 6-31G $(\mathrm{d}, \mathrm{p})$ basis atomic set for the validation of structure, reaction and mechanism. Molecular orbital energies, nonlinear optical properties, bond length, bond angles, reactivity, electrophilic and nucleophilic regions were delineated. Influence of various reactants on rate of chemical reaction were also ascertained and elucidated spectro-photometrically. Activation parameters have been assessed using Arrhenius-Eyring plots. A suitable mechanism consistent with observed kinetic results had been implicated and rate law deduced. Copyright (c) 2020 BCREC Group. All rights reserved
\end{abstract}

Keywords: Kinetics; Oxidation; Diclofenac sodium; NaIO4; Os(VIII) catalysis; DFT

How to Cite: Gupta, M., Srivastava, A., Srivastava, S. (2020). Sodium Periodate as a Selective Oxidant for Diclofenac Sodium in Alkaline Medium: A Quantum Chemical Approach. Bulletin of Chemical Reaction Engineering \& Catalysis, 15(2), 545-560 (doi:10.9767/bcrec.15.2.7555.545-560)

Permalink/DOI: https://doi.org/10.9767/bcrec.15.2.7555.545-560

\section{Introduction}

In a chemical reaction, if all reagents along with catalyst are in similar phase then reaction is regarded as homogenous. In such cases, catalysts are deliberated as solute in liquid reactants. Practically homogenous catalysis is more

* Corresponding Author.

E-mail: guptamadhu30@rediffmail.com (M. Gupta) alluring, because it has a discriminating nature towards desired product formation. Hence, their mechanisms are more approachable than heterogeneous catalysis for detailed investigation. In latest years several platinum group metal ions, including $\mathrm{Ru}(\mathrm{III}), \mathrm{Os}(\mathrm{VIII}), \mathrm{Ir}(\mathrm{III}), \mathrm{Rh}(\mathrm{III})$, and $\operatorname{Pd}(\mathrm{II})$, were extensively used as catalysts due to their strong catalytic influences in a variety of reactions [1-2]. The role of osmium(VIII), as a catalyst in some redox reactions, had been re- 
viewed [3-4]. Sodium periodate, an inorganic salt comprises a periodate anion and sodium cation, which can also be referred as sodium salt of periodic acid. During oxidation it reduces to periodite as stable product [5-6]. When our investigation had been done without mercuric acetate then reaction mixtures approach to pale yellow color. This yellow color manifested the formation of molecule due to interaction of iodide ion in oxidant. Because of this parallel reaction, there is hindrance in main oxidation reaction. Hence, iodide ion has to be discharged to obstruct the formation of iodine molecule. Here, mercuric acetate is utilized as scavenger or trapping agent for iodide ion. When $\mathrm{I}^{-}$comes in contact of mercuric acetate, it forms a complex $\left[\mathrm{Hg}(\mathrm{I})_{4}\right]^{2-}$ and $\mathrm{I}^{-}$get trapped in this complex. In this way parallel reaction gets discontinued with the help of mercuric acetate.

Diclofenac sodium (DFS), i.e. $[o-[(2,6-$ dichlorophenyl) amino]phenyl] sodium acetate, pertains with the non-steroidal antiinflammatory drugs. There is a necessity to proliferate a simple and economical method for the probation of DFS in pharmaceutical preparations. This drug belongs to non-steroidal anti-inflammatory drugs (NSAIDs). It has several applications in medical field like analgesic, antipyretic and anti-inflammatory [7]. Although it has been acknowledged for its efficient role relieving pain of inflammation and primary dysmenorrhea, anti-inflammatory action and inhibits prostaglandin synthesis, but its mode of action is still not known clearly. It has also been employed in treatment of osteoarthritis, rheumatoid arthritis and ankylosing spondylitis [8]. Because of its least solubility, commercially it exists in form its sodium salt.

On the basis of above results obtained after completion of reaction, we analyzed that $\mathrm{pH}$ value plays paramount role for reaction. The rate constants for slowest step and other equilibrium constants are helpful for elucidation of reaction mechanism. The mechanism elaborated is a consequence of all experimental data, spectral, kinetic and mechanistic studies. The negligible effect of ionic strength and dielectric constant shows that there is a reaction between neutral and charged species. The values of $\Delta H$ and $\Delta S$ favors given reactions. In all cases the negative value of $\Delta S$ shows that intermediate is more ordered then reactants [9]. For theoretical study all quantum chemical calculations were executed at level of density functional theory (DFT) with B3LYP function using 6-31G (d,p) basis atomic set for the validation of structure, reaction and mechanism. Polarizability and hyper-polarizabilities values have been calculated along with NLO and NBO computations of the product [10]. Global reactivity descriptors, like ionization potential, electron affinity, electronegativity, electrophilicity index and chemical potential, have been computed to predict the reactivity of the molecule. These DFT calculations also help in the interpretation of complex formed during experimental conditions [11$15]$.

So far, there was no report on the kinetics of DFS oxidation by alkaline sodium periodate in presence of Os(VIII) catalyst. Due to pharmaceutical importance of DFS and complexity of proposed reaction, a detailed study of this reaction becomes important. This study aims to check the reactivity of DFS towards sodium periodate in Os(VIII) catalyzed reaction and also elucidate the active species of catalyst and oxidant. With the help of kinetic and spectral results, we arrive at a suitable mechanism and also compute thermodynamic quantities for various steps. All the quantities and facts are further verified by using computational approach towards reaction. Hence we could compare theoretical and experimental data. The elucidation of mechanism allows chemistry to be interpreted, understood and predicted.

\section{Materials and Methods}

\subsection{Kinetic Measurements}

The progression of reaction was pursued iodometrically and also confirmed spectrophotometrically at various temperatures. It was authenticated that there was no significant interference from other species present in the reaction mixture at this condition. The reaction was observed to more than $85 \%$ completion of the reaction. The orders for various species were elucidated from the slopes of plots of log reaction rate versus log of respective concentrations of species. The rate constants were reproducible within $\pm 5 \%$. Regression analysis of experimental data to procure regression coefficient ' $r$ ' and the standard deviation ' $S$ ', of points from the regression line, was performed with the Origin 6.0 professional.

\subsection{Computational Quantum-Chemical Methods}

All calculations were performed using Gauss-View 5.0.8 software [16]. The geometries of the ground state were fully optimized using the most popular B3LYP method [17], applying 6-31-G (d,p) [18] of basis sets without symmetry constraints and using default convergence criteria. The optimized structure ob- 
tained after this computational study is helpful to study various parameters of both reactants and products, like bond length, bond angles, dipole moment, optical properties, etc. The output file of optimized structure was further used to run the file of energy, NLO, NBO, etc. which were helpful to define UV, MESP, optical properties, bond order etc. for that particular substrate. The approximation of the equations of the polarizing continuum (IEEPCM) [19] was used to consider the influence of a bulk solution at the same level. The charge of atoms was calculated by the semi-empirical quantumchemical method of Hückel [20].

\section{Results and Discussions}

\subsection{Stoichiometry and Product Analysis}

The results indicated 1:2 stoichiometry between substrate and oxidant. The oxidation product of DFS oxidation was extracted with ether and recrystallised with aqueous alcohol. Only one product, i.e. [2-(2,6-dichlorophenylamino)-phenyl]-methanol, was isolated with the help of preparative TLC and other separation technique and characterized by UV and FT-IR spectral studies. The product was further confirmed by its characteristic IR spectrum (Figure 1). The absence of a sharp band (peak) at $1695 \mathrm{~cm}^{-1}$ (due to the acidic carbonyl in DFS) confirms the nature of the product. Further, the secondary amine $(-\mathrm{NH})$ group observed around $3387 \mathrm{~cm}^{-1}$ in DFS is retained in the product. All these observations proved the formation of [2-(2,6-dicloro-phynylamino)phenyl]-methanol as the major product. For the confirmation of product, spectrophotometer is calibrated by using distilled water as solvent and then formation of [2-(2,6-dicloro-

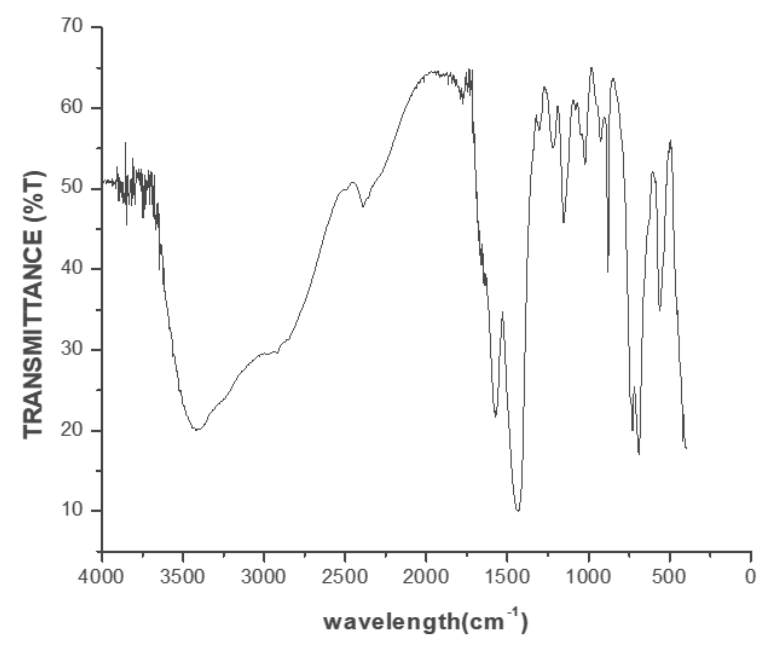

Figure 1. FT-IR spectrum of DFS oxidation product. phynylamino)-phenyl]-methanol as the oxidation product of DFS was confirmed by the peak around $262 \mathrm{~nm}$ ultraviolet spectrum which was recorded in the region 200-900 $\mathrm{nm}$ on UVvisible Double-Beam Spectrophotometer (systronic-2203) instrument with methanol as a solvent. The reaction products do not undergo further oxidation under the existing kinetic conditions (Scheme 1).

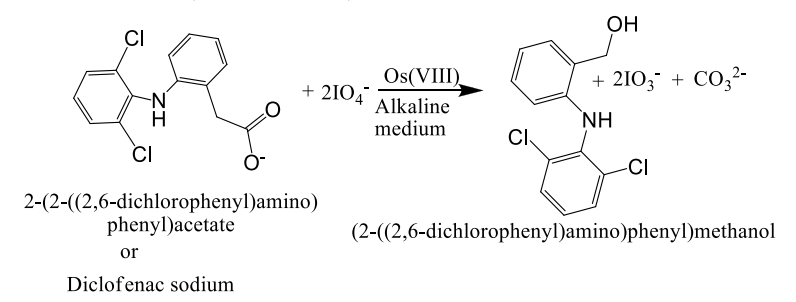

Scheme 1. Catalytic oxidation of diclofenac sodium

\subsection{Kinetic Analysis}

3.2.1 Reactivity of sodium periodate in alkaline medium

For determination of order of reaction with respect to sodium periodate at $35{ }^{\circ} \mathrm{C}$ in presence of Os(VIII) to oxidize diclofenac sodium by sodium periodate in alkaline medium various experiments were performed and the results are tabulated in Table 1. The concentration of $\left[\mathrm{NaIO}_{4}\right]$ varies from $0.83 \times 10^{-3}$ to $5.00 \times 10^{-3} \mathrm{M}$ at constant concentration of other reactants. At fixed time (5 min.) rate of reaction for each kinetic run was determined by the slope of tangent. This Table 1 represents that rate of reaction is directly proportional to concentration of $\mathrm{NaIO}_{4}$ which means increase in concentration of $\mathrm{NaIO}_{4}$ also increases the rate of reaction. This first order kinetics is confirmed by linearity of the plot of $\log \left[\mathrm{NaIO}_{4}\right]$ vs. $\log (-\mathrm{d} c / \mathrm{d} t)(r \geq$

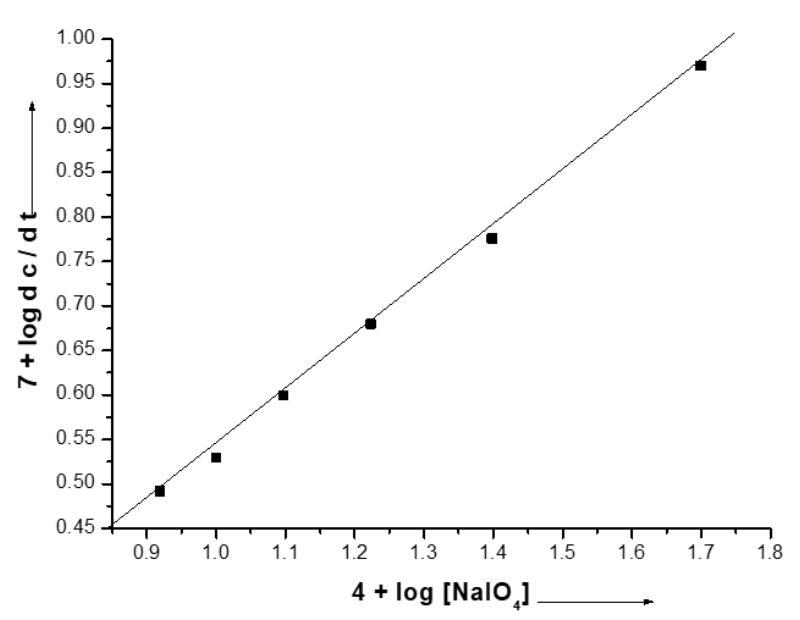

Figure 2. Plot of $\log \left[\mathrm{NaIO}_{4}\right]$ vs. $\log (\mathrm{d} c / \mathrm{d} t)$ for oxidation of [DFS] at $35^{\circ} \mathrm{C}$. 
$0.99, S \leq 0.062)$ up to $85 \%$ completion of reaction (Figure 2). The first order kinetics is also supported by constant value of $k_{1}$ given in Table 1 and it was further confirmed by least square method (Figure 3).

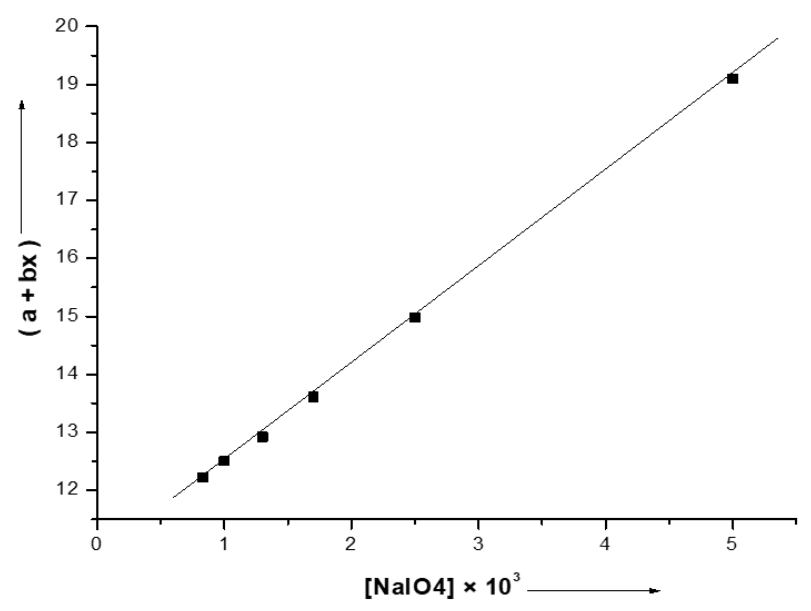

Figure 3. Plot of $\left[\mathrm{NaIO}_{4}\right]$ vs. $(\mathrm{a}+\mathrm{bx})$.

\subsubsection{Effect of Osmium(VIII) Tetra Oxide}

There are number of experiments which have been performed with different concentration of Os(VIII), while keeping concentration of other reactants constant at $35{ }^{\circ} \mathrm{C}$, in order to

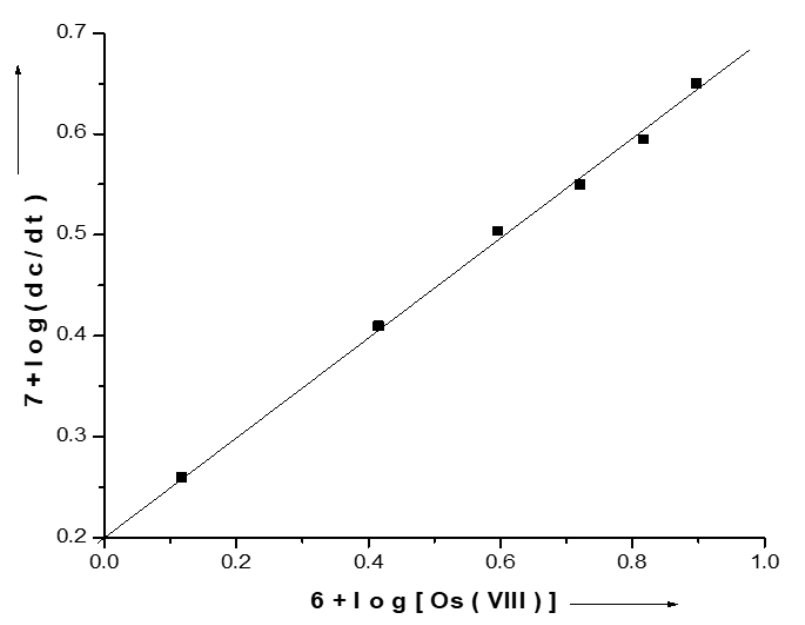

Figure 4. Plot of $\log [\mathrm{Os}(\mathrm{VIII})]$ vs. $\log (\mathrm{d} c / \mathrm{d} t)$ for oxidation of DFS at $35^{\circ} \mathrm{C}$.

Table 1. Effect of Variation of $\left[\mathrm{NaIO}_{4}\right]$, [DFS], [OH-], [ $\left.\mathrm{IO}_{4}^{-}\right]$and [Os(VIII)] on the Osmium(VIII) Catalysed Oxidation of PAM by sodium periodate in Aqueous Alkaline Medium at $303 \mathrm{~K}$ and I = 0.005 mol.dm ${ }^{-3}$

\begin{tabular}{|c|c|c|c|c|c|c|}
\hline $\begin{array}{c}{\left[\mathrm{NaIO}_{4}\right] \times 10^{3}} \\
\left(\mathrm{~mol}_{\mathrm{dm}} \mathrm{dm}^{-3}\right)\end{array}$ & $\begin{array}{c}{[\mathrm{S}] \times 10^{2}} \\
\left(\mathrm{~mol} . \mathrm{dm}^{-3}\right)\end{array}$ & 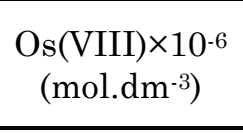 & $\begin{array}{c}{[\mathrm{NaOH}] \times 10^{3}} \\
\left(\mathrm{~mol}^{2} \mathrm{dm}^{-3}\right)\end{array}$ & $\begin{array}{l}{\left[\mathrm{Hg}(\mathrm{OAc})_{2}\right] \times 10^{3}} \\
\quad\left(\mathrm{~mol}^{3} \mathrm{dm}^{-3}\right)\end{array}$ & $\begin{array}{c}(-\mathrm{dc} / \mathrm{d} t) \times 10^{7} \\
\left(\mathrm{~mol} \cdot \mathrm{dm}^{-3} \cdot \mathrm{s}^{-1}\right) \\
\mathrm{DFS}\end{array}$ & $\begin{array}{l}k_{1} \times 10^{2} \\
\text { (Observed) }\end{array}$ \\
\hline 0.83 & 1.00 & 2.6 & 1.00 & 1.25 & 3.10 & 4.13 \\
\hline 1.00 & 1.00 & 2.6 & 1.00 & 1.25 & 3.20 & 4.05 \\
\hline 1.25 & 1.00 & 2.6 & 1.00 & 1.25 & 3.24 & 4.00 \\
\hline 1.67 & 1.00 & 2.6 & 1.00 & 1.25 & 4.32 & 4.17 \\
\hline 2.50 & 1.00 & 2.6 & 1.00 & 1.25 & 5.32 & 4.16 \\
\hline 5.00 & 1.00 & 2.6 & 1.00 & 1.25 & 9.82 & 4.23 \\
\hline 1.00 & 1.00 & 1.31 & 1.00 & 1.25 & 1.60 & 2.11 \\
\hline 1.00 & 1.00 & 3.94 & 1.00 & 1.25 & 2.49 & 4.53 \\
\hline 1.00 & 1.00 & 5.25 & 1.00 & 1.25 & 2.70 & 5.29 \\
\hline 1.00 & 1.00 & 6.56 & 1.00 & 1.25 & 3.40 & 6.67 \\
\hline 1.00 & 1.00 & 7.88 & 1.00 & 1.25 & 3.60 & 8.18 \\
\hline 1.00 & 0.13 & 2.6 & 1.00 & 1.25 & 2.10 & 2.82 \\
\hline 1.00 & 0.17 & 2.6 & 1.00 & 1.25 & 2.20 & 2.97 \\
\hline 1.00 & 0.25 & 2.6 & 1.00 & 1.25 & 2.31 & 3.07 \\
\hline 1.00 & 0.50 & 2.6 & 1.00 & 1.25 & 2.30 & 3.19 \\
\hline 1.00 & 2.00 & 2.6 & 1.00 & 1.25 & 2.40 & 3.48 \\
\hline 1.00 & 1.00 & 2.6 & 0.83 & 1.25 & 3.30 & 5.40 \\
\hline 1.00 & 1.00 & 2.6 & 1.25 & 1.25 & 2.80 & 4.38 \\
\hline 1.00 & 1.00 & 2.6 & 1.67 & 1.25 & 2.70 & 4.50 \\
\hline 1.00 & 1.00 & 2.6 & 2.50 & 1.25 & 2.60 & 3.61 \\
\hline 1.00 & 1.00 & 2.6 & 5.00 & 1.25 & 2.40 & 2.79 \\
\hline 1.00 & 1.00 & 2.6 & 1.00 & 0.83 & 4.00 & 4.65 \\
\hline 1.00 & 1.00 & 2.6 & 1.00 & 1.00 & 4.30 & 4.83 \\
\hline 1.00 & 1.00 & 2.6 & 1.00 & 1.67 & 3.20 & 3.33 \\
\hline 1.00 & 1.00 & 2.6 & 1.00 & 2.50 & 3.14 & 4.36 \\
\hline 1.00 & 1.00 & 2.6 & 1.00 & 5.00 & 2.75 & 3.49 \\
\hline
\end{tabular}


determine the dependence of reaction concentration with respect to $\mathrm{Os}(\mathrm{VIII})$. The concentration of $\mathrm{Os}(\mathrm{VIII})$ ranges from $1.31 \times 10^{-6} \mathrm{M}$ to $7.88 \times 10^{-6} \mathrm{M}$. The linear relationship between $\log [\mathrm{Os}(\mathrm{VIII})]$ and $\log (-\mathrm{d} c / \mathrm{d} t)(r \geq 0.99, \mathrm{~S} \leq$ $0.0021)$ up to $85 \%$ completion of reaction (Figure 4). Figure 4 also shows that order of reaction is unity with respect to $\mathrm{Os}(\mathrm{VIII})$ throughout the reaction. These results are also confirmed by least square method (Figure 5).

\subsubsection{Effect of alkaline medium}

In case of oxidation of DFS, the reaction order with respect to $\left[\mathrm{OH}^{-}\right]$is evaluated by various reaction experiments performed at $35{ }^{\circ} \mathrm{C}$ keeping all other reactants constant. The results of reaction are given in Table 1, in which sodium hydroxide concentration ranges from $0.83 \times 10^{-3} \mathrm{M}$ to $5.00 \times 10^{-3} \mathrm{M}$, keeping constant concentration of other reactants. These results

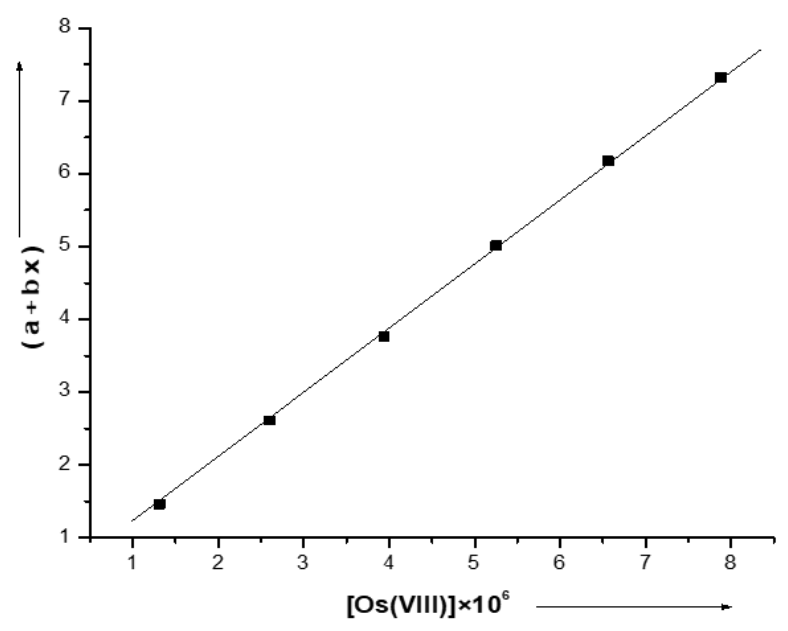

Figure 5. Plot between $(\mathrm{a}+\mathrm{bx})$ vs. $[\mathrm{Os}(\mathrm{VIII})] \times 10^{6}$ for oxidation of DFS at $35^{\circ} \mathrm{C}$.

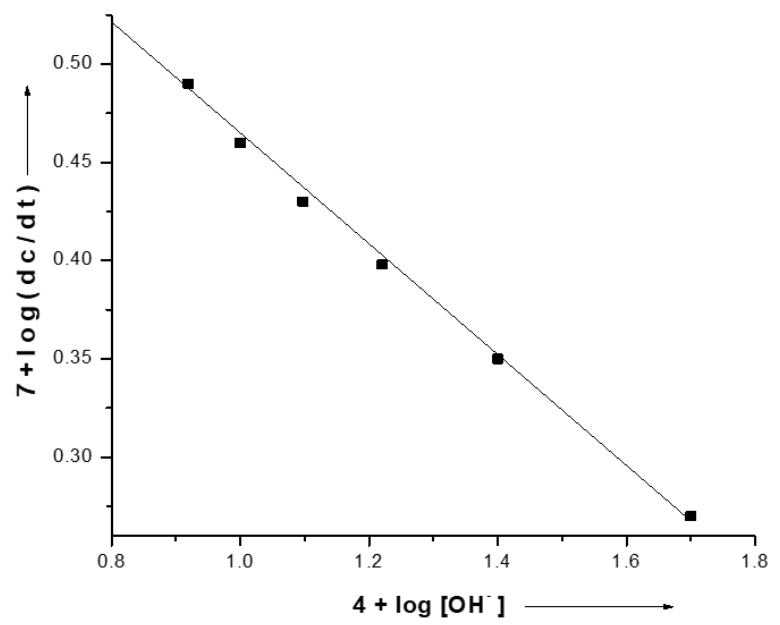

Figure 6. Plot of $\log [\mathrm{NaOH}]$ vs. $\log (\mathrm{dc} / \mathrm{dt})$ for oxidation of DFS at $35^{\circ} \mathrm{C}$. may conclude that as the concentration of sodium hydroxide increases reaction rate decreases. Therefore reaction has negative effect with respect to hydroxide ion which is ascertained by the plot of $\log [\mathrm{NaOH}]$ vs. $\log (-\mathrm{d} c / \mathrm{d} t)$ up to $90 \%$ completion of reaction (Figure 6 ).

3.2.4 Effect of substrate, heavy water addition, ionic strength, and dielectric constant

The effect of substrate was studied in the range of $0.13 \times 10^{-2}$ to $2.0 \times 10^{-2} \mathrm{~mol} . \mathrm{dm}^{-3}$ at constant concentrations of $\mathrm{NaIO}_{4}, \mathrm{OH}^{-}, \mathrm{IO}_{4}^{-}$, Os(VIII) and a constant ionic strength of 0.20 mol. $\mathrm{dm}^{-3}$. The order with respect to [DFS] was fractional order. This was also justified by the plot of $\log \mathrm{d} c / \mathrm{d} t$ versus [DFS] $(r \geq 0.9979, S \leq$ 0.017) (Figure 7). In alkaline medium different proportions of $\mathrm{D}_{2} \mathrm{O}$ and $\mathrm{H}_{2} \mathrm{O}$ have been used to study and determine the effect of addition of deuterium oxide $\left(\mathrm{D}_{2} \mathrm{O}\right)$ in $\mathrm{Os}(\mathrm{VIII})$ catalyzed oxidation of pharmaceutical drugs (acetyl salicylic acid, acetaminophen and diclofenac sodium). The percentages of $\mathrm{D}_{2} \mathrm{O}$ with $\mathrm{H}_{2} \mathrm{O}$ in experiments are $0-100,5-95,10-90$, and $20-80$. The results of experiments are summarized no effect of heavy water on rate of reaction. So in order to justify current reaction mechanism we can say that there is no involvement of protonated reducing pharmaceutical drugs.

The ionic strength of any reaction provides the importance of Debye-Huckel limiting law and if the rate of reaction is proportional to concentration of activated complex then its validity is justified. Debye-Huckel gave the following equation to represent the relationship between activity coefficient and ionic strength-

$$
\log _{10} k=\log _{10} k_{0}+1.02 Z_{A} Z_{B} \sqrt{\mu}
$$

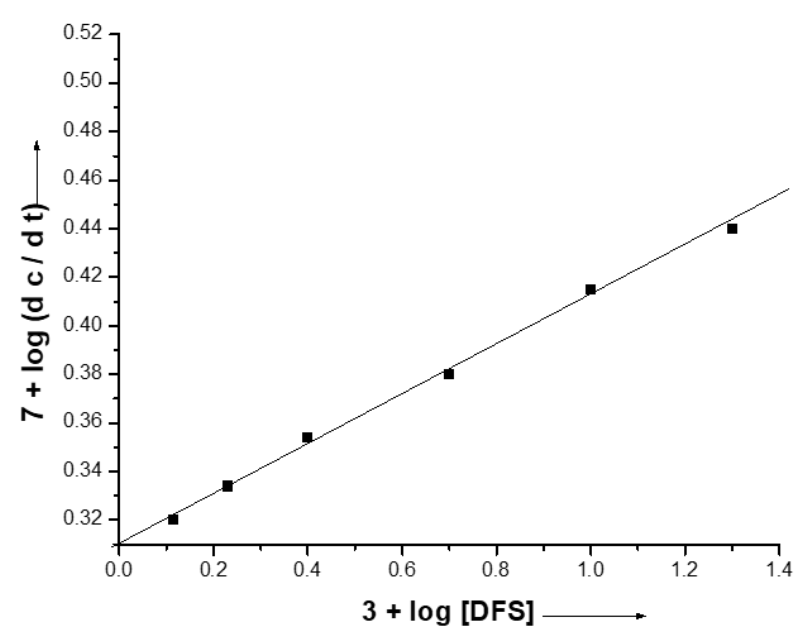

Figure 7. Plot of $3+\log [\mathrm{DFS}]$ vs. $7+\log (\mathrm{d} c / \mathrm{d} t)$. 
When the ionic strength varies in alkaline medium, this equation is reliable for measuring the rate of ionic reaction. A plot between $\log _{10} \mathrm{k}$ versus $\gamma_{\mu}$ will give a straight line of slope $1.02 \mathrm{Z}_{\mathrm{A}} \mathrm{Z}_{\mathrm{B}}$. If the molecule is neutral, value of $\mathrm{Z}_{\mathrm{A}} \mathrm{Z}_{\mathrm{B}}$ is zero then rate is independent of ionic strength. Alternatively, if $\mathrm{Z}_{\mathrm{A}} \mathrm{Z}_{\mathrm{B}}$ is non-zero then ionic strength affects the rate of reaction. In our investigation we added $\mathrm{KClO}_{3}$ in reaction mixture to elaborate the effect of ionic strength on reaction rate. In present investigation concentration of $\mathrm{KClO}_{3}$ varies from $0.83 \times 10^{-3} \mathrm{M}$ to $5.00 \times 10^{-3} \mathrm{M}$ at constant concentration of all other reactants at $35{ }^{\circ} \mathrm{C}$. The results prove that ionic strength has no effect on reaction rate and there is not certain alteration in $\mathrm{d} c / \mathrm{d} t$ values.

3.3 Computational Details of Os(VIII) catalyzed oxidation of diclofenac sodium by sodium periodate in alkaline medium

\subsubsection{Crystal Structure and Molecular Geome- try}

The calculated and experimental structure (Figure 8) of diclofenac sodium has longest distance between $\mathrm{O} 29-\mathrm{Na} 30$ is established to be $2.18 \AA$, due to interaction of carboxylate and sodium metal. The distance between $\mathrm{C} 2-\mathrm{Cl} 22$ and $\mathrm{C} 4-\mathrm{C} 23$ are $1.76 \AA$ and $1.77 \AA$, respectively, because of interaction between lone pair of halogens and carbon atoms.

Due to the delocalization of nonbonding electrons from N10 to both phenyl rings the bond length between $\mathrm{N} 10-\mathrm{H} 11$ becomes shortest one, i.e. $1.01 \AA$. All $\mathrm{C}-\mathrm{C}$ and $\mathrm{C}-\mathrm{H}$ bond distances of rings are in the range 1.50-1.54 $\AA$ and 1.09-1.11 ̊, respectively (Table 2). The sym- metry of the molecule, with chloride substituent and $\mathrm{N}$-substituted phenyl ring with a carboxylate ion, yields distortion in ring angles than $120^{\circ}$. The delocalization of non-bonding electrons of N10 results increase in bond angle $\left(129.29^{\circ}\right)$ than customary $120^{\circ}$ while the $\mathrm{C}-\mathrm{O}-\mathrm{Na}$ has least bond angle, i.e. $87.24^{\circ}$.

Product was obtained as needle shaped crystal by slow evaporation of water solvent at room temperature and crystallized in triclinic system with space group $\mathrm{C}_{1}$, with unit cell parameters $a=0.269287, b=0.272785$ and $c=$ 0.443140 . In product the computational calculated and experimental longest distance between $\mathrm{C} 8-\mathrm{Cl} 14$ and $\mathrm{C} 12-\mathrm{Cl} 15$ are $1.75 \AA$ and $1.76 \AA$, respectively. Meanwhile, other $\mathrm{C}-\mathrm{C}$ have bond length analogous to the experimental value $(1.54 \AA)$, and this was exactly similar for all $\mathrm{C}-\mathrm{C}$ bonds and the smallest bond lengths are in between $\mathrm{H} 28-\mathrm{O} 17$, i.e. $0.9666 \AA$ A. Some bond angles $\mathrm{C}-\mathrm{N}-\mathrm{C}$ are above $120^{\circ}$ due lone pair electrons of nitrogen atom. Other $\mathrm{C}-\mathrm{C}-\mathrm{C}$ are not much distorted from customary $120^{\circ}$. The resemblance between the optimized and experimental crystal structure is good enough displaying that the optimized structure is almost similar to the experimental structure. The existence of lone pair of electrons, electronegativity of the oxygen, nitrogen and chlorine atom causes distortion in bond angle and bond length.

\subsubsection{Electronic absorption}

Formation of [2-(2,6-dichlorophenylamino)phenyl]-methanol as the oxidation product of diclofenac sodium was assured by the peak

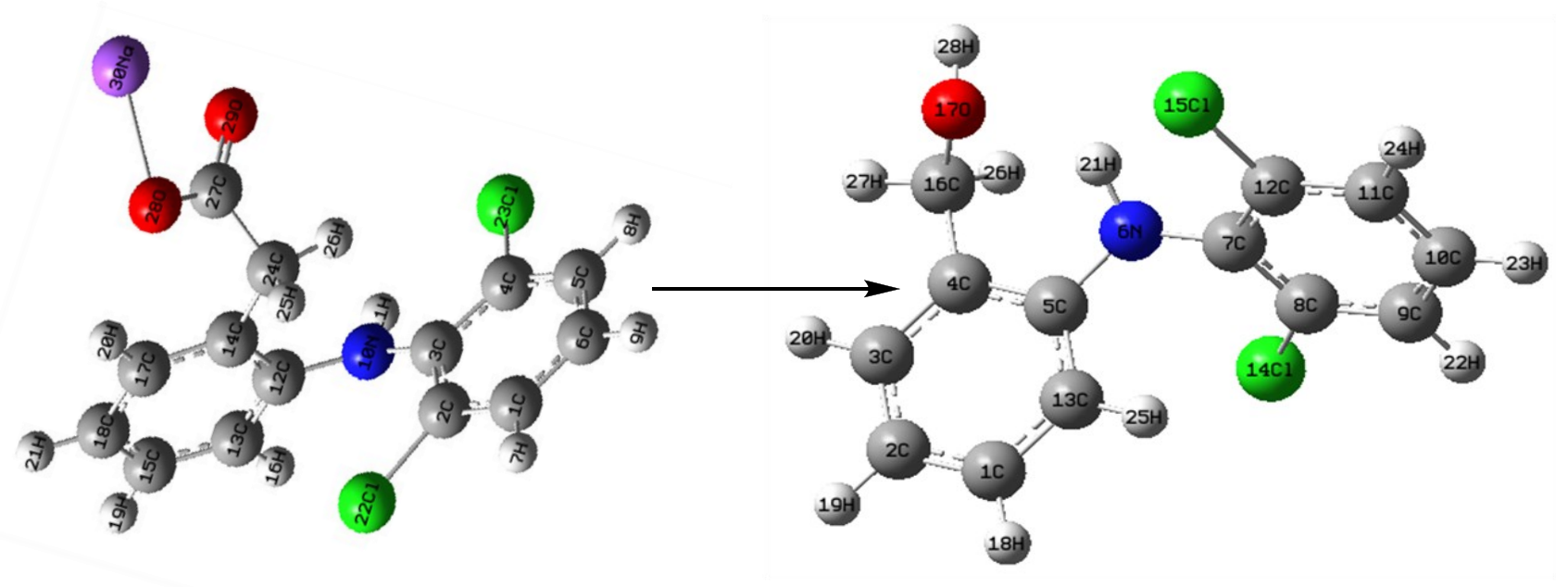

Figure 8. Optimized structure of reactant (Diclofenac sodium) and product ([2-(2,6dichlorophenylamino)-phenyl]-methanol).

$\bigcirc$ sodium, $\bigcirc$ Oxygen, $\bigcirc$ chlorine, $\bigcirc$ carbon, $\bigcirc$ Hydrogen 
Table 2. Comparison of bond length and bond angles of optimized structural parameters for diclofenac sodium and oxidation product, i.e. [2-(2,6-dichlorophenylamino)-phenyl]-methanol using B3LYP/6-31G (d,p) method.

\begin{tabular}{|c|c|c|c|c|c|c|c|}
\hline \multicolumn{4}{|c|}{ Diclofenac sodium } & \multicolumn{4}{|c|}{ Oxidation product } \\
\hline \multicolumn{2}{|c|}{ Bond length $\left(\mathrm{A}^{\circ}\right)$} & \multicolumn{2}{|c|}{ Bond Angle $\left(^{\circ}\right)$} & \multicolumn{2}{|c|}{ Bond length $\left(\mathrm{A}^{\circ}\right)$} & \multicolumn{2}{|c|}{ Bond Angle ( $\left.{ }^{\circ}\right)$} \\
\hline $\mathrm{C} 2-\mathrm{C} 1$ & 1.39316 & $\mathrm{C} 3-\mathrm{C} 2-\mathrm{C} 1$ & 122.148 & $\mathrm{C} 2-\mathrm{C} 1$ & 1.39417 & $\mathrm{C} 3-\mathrm{C} 2-\mathrm{C} 1$ & 119.037 \\
\hline C3-C2 & 1.41621 & C4-C3-C2 & 114.904 & $\mathrm{C} 3-\mathrm{C} 2$ & 1.39519 & C4-C3-C2 & 121.449 \\
\hline $\mathrm{C} 4-\mathrm{C} 3$ & 1.41904 & C5-C4-C3 & 123.38 & $\mathrm{C} 4-\mathrm{C} 3$ & 1.39538 & C5-C4-C3 & 119.061 \\
\hline $\mathrm{C} 5-\mathrm{C} 4$ & 1.38794 & $\mathrm{C} 6-\mathrm{C} 1-\mathrm{C} 2$ & 120.684 & $\mathrm{C} 5-\mathrm{C} 4$ & 1.41343 & N6-C5-C4 & 117.524 \\
\hline $\mathrm{C} 6-\mathrm{C} 1$ & 1.39149 & $\mathrm{H} 7-\mathrm{C} 1-\mathrm{C} 6$ & 120.81 & N6-C5 & 1.41046 & C7-N6-C5 & 125.561 \\
\hline $\mathrm{H} 7-\mathrm{C} 1$ & 1.08413 & H8-C5-C4 & 119.186 & $\mathrm{C} 7-\mathrm{N} 6$ & 1.39382 & $\mathrm{C} 8-\mathrm{C} 7-\mathrm{C} 6$ & 122.976 \\
\hline H8-C5 & 1.08394 & H9-C6-C1 & 120.397 & $\mathrm{C} 8-\mathrm{C} 7$ & 1.41389 & $\mathrm{C} 9-\mathrm{C} 8-\mathrm{C} 7$ & 122.126 \\
\hline H9-C6 & 1.08445 & N10-C6-C2 & 125.143 & $\mathrm{C} 9-\mathrm{C} 8$ & 1.39286 & C10-C9-C8 & 120.024 \\
\hline N10-C6 & 1.38186 & H11-N10-C3 & 113.493 & C10-C9 & 1.39266 & C11-C10-C9 & 119.807 \\
\hline H11-N10 & 1.01061 & C12-N10-C3 & 129.291 & $\mathrm{C} 11 \mathrm{C} 10$ & 1.3928 & C12-C11-C10 & 119.493 \\
\hline $\mathrm{C} 12-\mathrm{N} 10$ & 1.43105 & C13-C12-N10 & 116.492 & $\mathrm{C} 12-\mathrm{C} 11$ & 1.39099 & $\mathrm{C} 13-\mathrm{C} 1-\mathrm{C} 2$ & 120.613 \\
\hline $\mathrm{C} 13-\mathrm{C} 12$ & 1.40129 & C14-C12-N10 & 123.171 & $\mathrm{C} 13-\mathrm{C} 1$ & 1.39361 & $\mathrm{Cl14-C8-C7}$ & 119.983 \\
\hline $\mathrm{C} 14-\mathrm{C} 12$ & 1.41003 & C15-C13-C12 & 120.967 & Cl14-C8 & 1.754 & Cl15-C12-C11 & 118.289 \\
\hline $\mathrm{C} 15-\mathrm{C} 13$ & 1.39058 & H16-C13-C12 & 118.296 & $\mathrm{Cl} 15-\mathrm{C} 12$ & 1.76025 & C16-C4-C3 & 120.915 \\
\hline $\mathrm{H} 16-\mathrm{C} 13$ & 1.08584 & C17-C14-C12 & 117.761 & $\mathrm{C} 16-\mathrm{C} 4$ & 1.50455 & O17-C16-C4 & 109.352 \\
\hline $\mathrm{C} 17-\mathrm{C} 14$ & 1.4034 & C18-C17-C14 & 121.769 & $\mathrm{O} 17-\mathrm{C} 16$ & 1.44008 & H18-C1-C13 & 119.208 \\
\hline $\mathrm{C} 18-\mathrm{C} 17$ & 1.39265 & H19-C15-C13 & 119.999 & H18-C1 & 1.08624 & $\mathrm{H} 19-\mathrm{C} 2-\mathrm{C} 1$ & 120.618 \\
\hline H19-C15 & 1.08605 & H20-C17-C14 & 117.796 & $\mathrm{H} 19-\mathrm{C} 2$ & 1.08528 & $\mathrm{H} 20-\mathrm{C} 3-\mathrm{C} 2$ & 119.862 \\
\hline $\mathrm{H} 20-\mathrm{C} 17$ & 1.08532 & H21-C18-C17 & 119.796 & $\mathrm{H} 20-\mathrm{C} 3$ & 1.08718 & H21-N6-C5 & 111.735 \\
\hline $\mathrm{H} 21-\mathrm{C} 18$ & 1.08639 & $\mathrm{Cl} 22-\mathrm{C} 2-\mathrm{C} 1$ & 117.012 & H21-N6 & 1.01668 & $\mathrm{H} 22-\mathrm{C} 9-\mathrm{C} 8$ & 119.027 \\
\hline $\mathrm{Cl} 22-\mathrm{C} 2$ & 1.75829 & $\mathrm{Cl} 23-\mathrm{C} 4-\mathrm{C} 3$ & 118.662 & $\mathrm{H} 22-\mathrm{C} 9$ & 1.08391 & H23-C10-C9 & 120.084 \\
\hline $\mathrm{Cl} 23-\mathrm{C} 4$ & 1.76758 & C24-C14-C12 & 122.094 & $\mathrm{H} 23-\mathrm{C} 10$ & 1.08484 & H24-C11-C10 & 121.128 \\
\hline $\mathrm{C} 24-\mathrm{C} 14$ & 1.52052 & H25-C24-C14 & 109.569 & $\mathrm{H} 24-\mathrm{C} 11$ & 1.08384 & H25-C13-C1 & 120.016 \\
\hline $\mathrm{H} 25-\mathrm{C} 24$ & 1.09658 & H26-C24-C14 & 110.242 & $\mathrm{H} 25-\mathrm{C} 13$ & 1.08448 & $\mathrm{H} 26-\mathrm{C} 16-\mathrm{C} 4$ & 109.434 \\
\hline $\mathrm{H} 26-\mathrm{C} 24$ & 1.08901 & C27-C24-C14 & 112.749 & $\mathrm{H} 26-\mathrm{C} 16$ & 1.10096 & $\mathrm{H} 27-\mathrm{C} 16-\mathrm{C} 4$ & 109.769 \\
\hline $\mathrm{C} 27-\mathrm{C} 24$ & 1.53417 & O28-C27-C24 & 118.063 & $\mathrm{H} 27-\mathrm{C} 16$ & 1.09812 & \multirow{4}{*}{ H28-O17-C16 } & \multirow{4}{*}{107.798} \\
\hline $\mathrm{O} 28-\mathrm{C} 27$ & 1.27441 & O29-C27-C24 & 117.859 & \multirow{3}{*}{$\mathrm{H} 28-\mathrm{O} 17$} & \multirow{3}{*}{0.96665} & & \\
\hline $\mathrm{O} 29-\mathrm{C} 27$ & 1.26882 & \multirow{2}{*}{ Na30-O29-C27 } & \multirow{2}{*}{87.2435} & & & & \\
\hline $\mathrm{Na} 30-\mathrm{O} 29$ & 2.18445 & & & & & & \\
\hline
\end{tabular}


around $262 \mathrm{~nm}$ ultraviolet spectrum which was recorded in the region 200-900 $\mathrm{nm}$ on UVvisible Double-Beam Spectrophotometer (systronic-2203) instrument with water as a solvent. The UV-Visible spectrum of reactant and compound have been studied by TD-DFT method using B3LYP and 6-31-G (d,p) basis sets. The UV data with excitation energies, oscillator strength $(f)$, percentage contribution of probable transitions and resultant absorption wavelengths have been analyzed with experimental results. The theoretical UV spectrum of DFS $(f=0.0404)$ in water has an intense electronic transition at $224 \mathrm{~nm}$ and $272 \mathrm{~nm}$ while
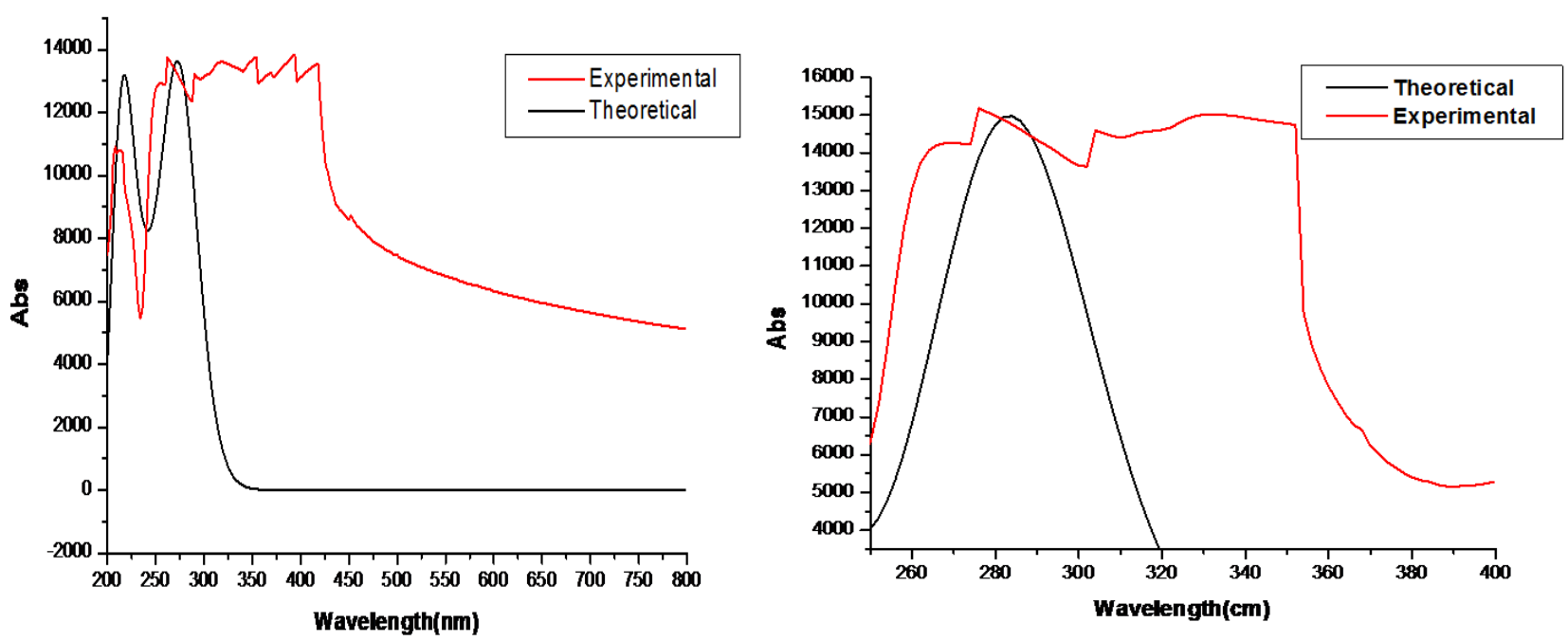

Figure 9. Experimental and theoretical UV-Visible spectrum of (a) diclofenac sodium (b) reaction product.
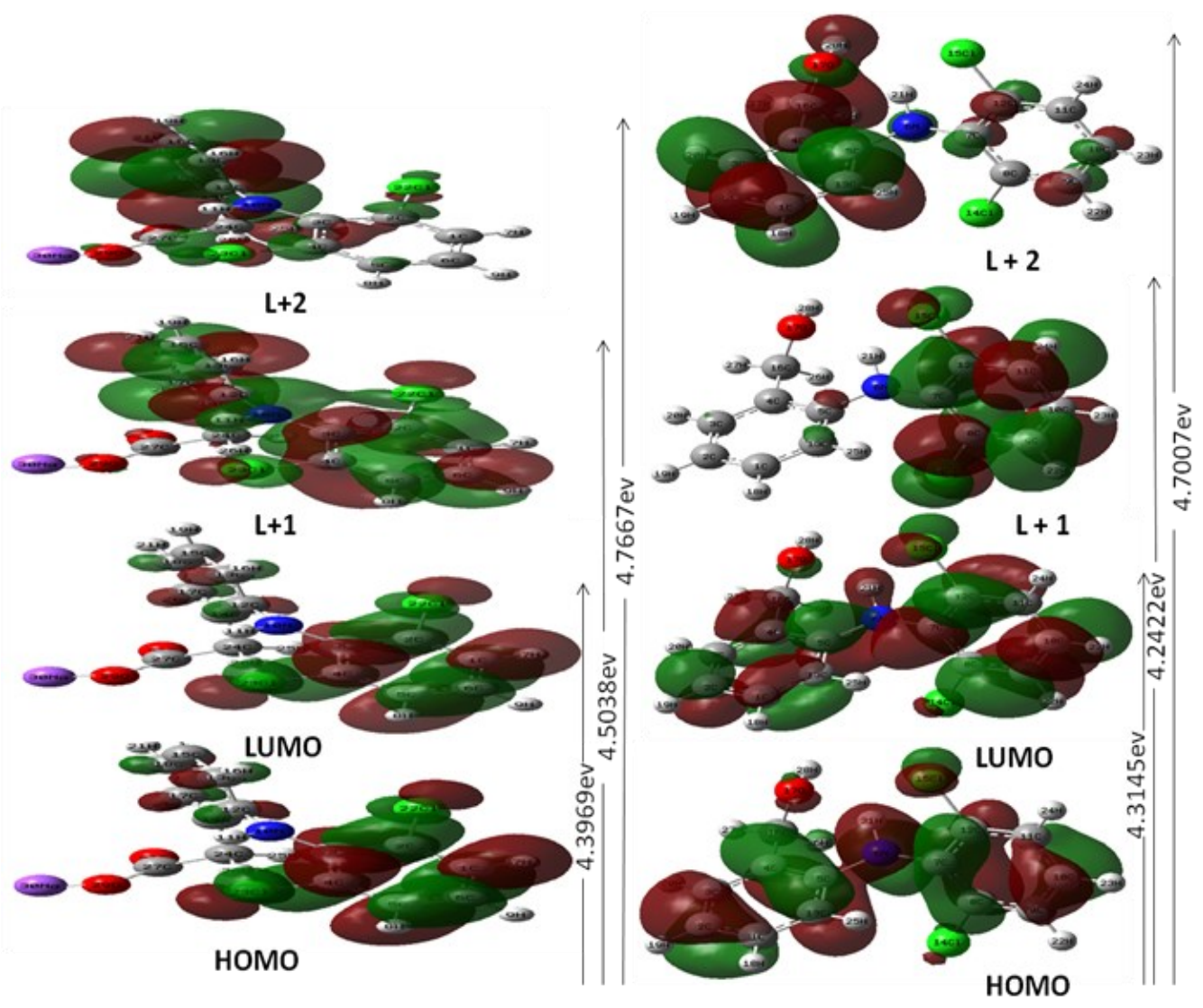

Figure 10. HOMO-LUMO transitions for diclofenac sodium and main product. 


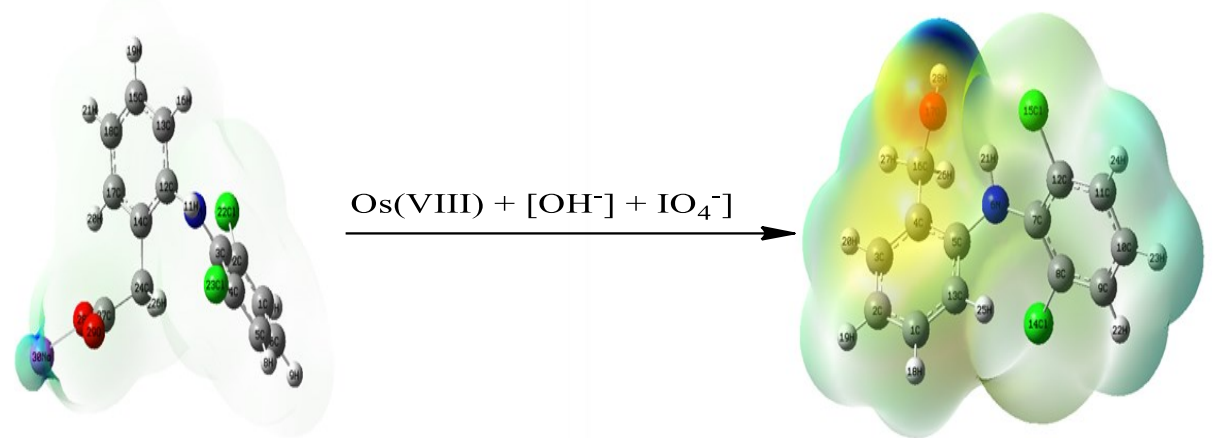

Figure 11. 3D plots of the molecular electrostatic potential of Diclofenacsodium and oxidation product.

Table 3. Second order perturbation theory analysis of Fock matrix in NBO basis of the [2-(2,6dichlorophenylamino)- phenyl]-methanol as oxidation product.

\begin{tabular}{|c|c|c|c|c|c|c|c|c|}
\hline Doner & Type & $\mathrm{ED} / \mathrm{e}$ & Acceptor(j) & Type & $\mathrm{ED} / \mathrm{e}$ & $\mathrm{E}(2) \mathrm{a}$ & $(\mathrm{Ej}-\mathrm{Ei}) \mathrm{b}$ & Fij(c) \\
\hline $\mathrm{C} 1-\mathrm{C} 2$ & л & -0.24161 & $\mathrm{C} 3-\mathrm{C} 4$ & $\pi^{*}$ & 1.67453 & 21.89 & 0.28 & 0.071 \\
\hline $\mathrm{C} 1-\mathrm{C} 2$ & л & -0.24161 & C5-C12 & $\pi^{*}$ & 1.67453 & 18.83 & 0.28 & 0.06 \\
\hline $\mathrm{C} 3-\mathrm{C} 4$ & л & -0.24362 & $\mathrm{C} 1-\mathrm{C} 2$ & $\pi^{*}$ & 1.68896 & 17.82 & 0.28 & 0.064 \\
\hline $\mathrm{C} 3-\mathrm{C} 4$ & л & -0.24362 & C5-C13 & $\pi^{*}$ & 1.68896 & 21.05 & 0.28 & 0.070 \\
\hline C16-O17 & $\mathrm{n}$ & -0.24362 & $\mathrm{C} 3-\mathrm{C} 4$ & $\pi^{*}$ & 1.68896 & 5.35 & 0.52 & 0.051 \\
\hline C5-C13 & л & -0.24824 & $\mathrm{C} 1-\mathrm{C} 2$ & $\pi^{*}$ & 1.64849 & 22.39 & 0.29 & 0.072 \\
\hline C5-C13 & л & -0.24824 & $\mathrm{C} 3-\mathrm{C} 4$ & $\pi^{*}$ & 1.64849 & 17.88 & 0.29 & 0.064 \\
\hline C7-C12 & л & -0.24123 & C8-C9 & $\pi^{*}$ & 1.66766 & 16.43 & 0.29 & 0.062 \\
\hline C7-C12 & л & -0.24123 & C10-C11 & $\pi^{*}$ & 1.66766 & 20.15 & 0.31 & 0.070 \\
\hline C8-C9 & л & -0.27770 & C7-C12 & $\pi^{*}$ & 1.70138 & 20.38 & 0.27 & 0.070 \\
\hline C8-C9 & л & -0.27770 & C10-C11 & $\pi^{*}$ & 1.70138 & 16.90 & 0.30 & 0.064 \\
\hline C10-C11 & л & -0.25861 & C7-C12 & $\pi^{*}$ & 1.65893 & 20.72 & 0.26 & 0.067 \\
\hline C10-C11 & л & -0.25861 & C8-C9 & $\pi^{*}$ & 1.65893 & 23.09 & 0.27 & 0.071 \\
\hline $\mathrm{C} 7-\mathrm{C} 12$ & л & -0.00317 & C8-C9 & $\pi^{*}$ & 0.45454 & 319.50 & 0.01 & 0.079 \\
\hline $\mathrm{C} 7-\mathrm{C} 12$ & л & -0.00317 & $\mathrm{C} 10-\mathrm{C} 11$ & $\pi^{*}$ & 0.45454 & 116.07 & 0.03 & 0.080 \\
\hline C8-C9 & л & -0.00720 & C10-C11 & $\pi^{*}$ & 0.00720 & 190.68 & 0.02 & 0.084 \\
\hline N6 & $\mathrm{n}$ & -0.26182 & C5-C13 & $\pi^{*}$ & 1.75295 & 27.44 & 0.30 & 0.083 \\
\hline N6 & $\mathrm{n}$ & -0.26182 & C7-C12 & $\pi^{*}$ & 1.75295 & 22.73 & 0.26 & 0.072 \\
\hline Cl14 & $\mathrm{n}$ & -0.32645 & C8-C9 & $\pi^{*}$ & 1.93103 & 11.38 & 0.33 & 0.060 \\
\hline Cl15 & $\mathrm{n}$ & -0.33022 & $\mathrm{C} 7-\mathrm{C} 12$ & $\pi^{*}$ & 1.93530 & 11.22 & 0.33 & 0.060 \\
\hline $\mathrm{O} 17$ & $\mathrm{n}$ & -0.34483 & N6-H21 & $\sigma^{*}$ & 1.94902 & 7.32 & 0.80 & 0.069 \\
\hline $\mathrm{O} 17$ & $\mathrm{n}$ & -0.34483 & C16-H27 & $\sigma^{*}$ & 1.94902 & 6.17 & 0.80 & 0.063 \\
\hline
\end{tabular}


product ( $f=0.0111$ ) has electronic transition at $286 \mathrm{~nm}$, which complies with the measured experimental data of DFS $(\lambda$ exp. $=262 \mathrm{~nm}$ and $288 \mathrm{~nm})$ and product $(\lambda$ exp. $=262 \mathrm{~nm}$ and 318 $\mathrm{nm})$, respectively (Figure 9).

These data corresponds to the transition from HOMO to LUMO with $64 \%, \mathrm{H}$ to $\mathrm{L}+1$ with $63 \%$ and $\mathrm{H}$ to $\mathrm{L}+2$ transition with $63 \%$ contribution due to $\pi \rightarrow \pi^{*}$ transition in diclofenac sodium . Product corresponds to the transition from HOMO to LUMO with $70 \%, \mathrm{H}$ to $\mathrm{L}+1$ with $69 \%$ and $\mathrm{H}$ to $\mathrm{L}+2$ with $66 \%$ contribution due to $л \rightarrow \pi^{*}$ transition (Figure 10). The given HOMO-LUMO of molecules represents the reactivity and kinetic sustainability their interaction. Since the energy gap between HOMO-LUMO least, so electron can be easily promoted from HOMO to LUMO. The molecular orbital diagram (Figure 10) shows that diclofenac sodium has more reactivity for proposed oxidation reaction.

\subsubsection{Molecular electrostatic potential}

The MEP value of diclofenac sodium around $\mathrm{O}_{7}$ is -1.419 and MEP values of [2-(2,6dichlorophenylamino)-phenyl]-methanol around -7.866 respectively. In oxidation product, $\mathrm{C} 7, \mathrm{C} 12$, and $\mathrm{C} 11$ is slightly electron rich in nature. The molecular electrostatic potential contour surface of diclofenac sodium and its oxidation product (Figure 11) shows that the negative regions are electrophilic regions, these are mainly over the oxygen atoms $\left(\mathrm{O}_{28}\right)$, while $\mathrm{O}_{29}$ is slightly electron deficient as MEP figure of diclofenac sodium depicted and $\mathrm{O}_{18}$ are slightly electron deficient in its oxidation product, the positive regions are the nucleophilic regions and these are over the carbon atoms connected with oxygen atom and over the hydrogen atoms of both the molecule. In both, the compounds chlorine atoms are neutral in nature while nitrogen atoms are electron deficient in nature.

\subsubsection{Non-bond orbital analysis}

NBO analysis has been performed on the molecule at the DFT/B3LYP/6-31G+ $(\mathrm{d}, \mathrm{p})$ level in order to elucidate the intramolecular and delocalization of electron density within the molecule, which are presented in Table 3. For oxidation product, $\mathrm{C} 7-\mathrm{C} 12$ of the NBO conjugated with $\pi^{*}$ (C8-C9) leads to an enormous stabilization of $319.50 \mathrm{~kJ} / \mathrm{mol}$. This strong stabilization denotes the larger delocalization. As the interaction around the ring increases the biological activity in the compound also enhanced. Second-order perturbation theory analysis of the Fock matrix in NBO basis for product is given in Table 3 and the correlation between donor (i), acceptor (j) and stabilization energy $\mathrm{E}(2)$ is given as:

$$
E(2)=\Delta E_{i j}=q_{i} \frac{\left(F_{i j}\right)^{2}}{\left(E_{i}-E_{j}\right)}
$$

where $q i=$ donor orbital occupancy, $E_{i}$ and $E_{j}=$ diagonal elements, and $F_{i j}=$ off diagonal NBO fock matrix element. The NBO analysis represents the intramolecular charge transfer in product as:

Table 4. Calculated Dipole moment $\left(\mu_{0}\right)$, Polarizability $\left(\left|\alpha_{0}\right|\right)$, First Hyperpolarizability $\left(\beta_{0}\right)$ and their components, using B3LYP/6-31G(d,p)

\begin{tabular}{|c|c|c|c|c|c|c|c|c|}
\hline \multicolumn{3}{|c|}{ Dipole moment } & \multicolumn{3}{|c|}{ Polarizability } & \multicolumn{3}{|c|}{ Hyperpolarizability } \\
\hline \multicolumn{2}{|c|}{ Diclofenac sodium } & \multirow{2}{*}{$\begin{array}{c}\begin{array}{c}\text { Oxidation } \\
\text { product }\end{array} \\
1.1057\end{array}$} & \multicolumn{2}{|c|}{ Diclofenac sodium } & \multirow{2}{*}{$\begin{array}{c}\begin{array}{c}\text { Oxidation } \\
\text { product }\end{array} \\
302.689\end{array}$} & \multicolumn{2}{|c|}{ Diclofenac sodium } & \multirow{2}{*}{$\begin{array}{c}\begin{array}{c}\text { Oxidation } \\
\text { product }\end{array} \\
755.059\end{array}$} \\
\hline$\mu_{\mathrm{x}}$ & -5.626 & & $\alpha \mathrm{xx}$ & 253.232 & & $\beta \mathrm{xxx}$ & -339.05 & \\
\hline$\mu_{\mathrm{Y}}$ & -4.5268 & 0.3489 & $\alpha \mathrm{XY}$ & -66.269 & 4.51117 & $\beta \mathrm{XXY}$ & -322.17 & -303.68 \\
\hline$\mu_{\mathrm{Z}}$ & 0.1938 & -1.481 & $\alpha_{Y Y}$ & 258.671 & 226.481 & $\beta \mathrm{XYY}$ & -42.042 & 130.073 \\
\hline \multirow[t]{8}{*}{$\mu$} & 7.2237 & 1.8808 & $\alpha x z$ & -11.371 & 12.1885 & $\beta \mathrm{YYY}$ & -174.51 & -119.62 \\
\hline & & & $\alpha \mathrm{YZ}$ & 0.8846 & -11.855 & $\beta x x z$ & -289.68 & 384.164 \\
\hline & & & $\alpha z z$ & 224.271 & 145.387 & $\beta \mathrm{XYZ}$ & 108.711 & 189.092 \\
\hline & & & $\alpha_{0}$ & 36.367 & 33.3231 & $\beta \mathrm{YYZ}$ & 371.866 & -71.439 \\
\hline & & & & & & $\beta x z z$ & 245.308 & -119.03 \\
\hline & & & & & & $\beta \mathrm{YZZ}$ & -57.9 & 27.3989 \\
\hline & & & & & & $\beta \mathrm{zzZ}$ & -351.32 & -39.24 \\
\hline & & & & & & $\begin{array}{l}\beta_{\text {TOTAL }} \\
(\mathrm{esu})\end{array}$ & 5.453 & 7.81577 \\
\hline
\end{tabular}

$\mu_{0}$ in Debye; $\left|a_{0}\right|$ and $\Delta a$ in $10^{-24} \mathrm{esu} ; \beta_{0}$ in $10^{-30} \mathrm{esu}$ 
- From bonding $\pi(\mathrm{C} 1-\mathrm{C} 2)$ to antibonding $\pi^{*}$ (C3-C4) and (C5-C13) with stabilization energy $21.89 \mathrm{kcal}^{\mathrm{mol}} \mathrm{l}^{-1}$ and $18.83 \mathrm{kcal} \cdot \mathrm{mol}^{-1}$.

- From bonding $\pi(\mathrm{C} 3-\mathrm{C} 4)$ to antibonding $\pi^{*}$ (C1-C2) and (C5-C13) with stabilization energy $17.82 \mathrm{kcal}^{\mathrm{mol}}{ }^{-1}$ and $21.05 \mathrm{kcal}^{\mathrm{mol}}{ }^{-1}$.

- From bonding $\mathrm{n}(\mathrm{C} 16-\mathrm{O} 17)$ to antibonding $\pi^{*}$ (C3-C4) with stabilization energy 5.35 kcal.mol-1.

- From bonding $\pi(\mathrm{C} 5-\mathrm{C} 13)$ to antibonding $\pi^{*}$ (C1-C2) and (C3-C4) with stabilization energy $22.39 \mathrm{kcal}^{\mathrm{mol}-1}$ and $17.88 \mathrm{kcal}^{\mathrm{mol}}{ }^{-1}$.

- From bonding $\pi(\mathrm{C} 7-\mathrm{C} 12)$ to antibonding $\pi^{*}$ (C8-C9) and (C10-C11) with stabilization energy $16.43 \mathrm{kcal}^{\mathrm{mol}}{ }^{-1}$ and $20.15 \mathrm{kcal}^{\mathrm{mol}}{ }^{-1}$.

- From bonding $\pi(\mathrm{C} 8-\mathrm{C} 9)$ to antibonding $\pi^{*}$ (C7-C12) and (C10-C11) with stabilization

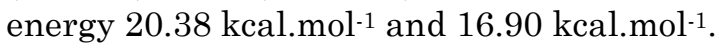

- From bonding $\pi(\mathrm{C} 10-\mathrm{C} 11)$ to antibonding $\pi^{*}$ (C7-C12) and (C8-C9) with stabilization energy $20.72 \mathrm{kcal}^{\mathrm{mol}}{ }^{-1}$ and $23.09 \mathrm{kcal}^{\mathrm{mol}}{ }^{-1}$.

- From bonding $\pi(\mathrm{C} 7-\mathrm{C} 12)$ to antibonding $\pi^{*}$ (C8-C9) and (C10-C11) with stabilization energy $319.50 \mathrm{kcal}^{\mathrm{mol}-1}$ and $116.07 \mathrm{kcal} . \mathrm{mol}^{-1}$.
- From bonding $\pi\left(\mathrm{C} 8\right.$-C9) to antibonding $\pi^{*}$ (C10-C11) with stabilization energy 190.68 kcal.mol-1.

- From LP (1) of N6 to $\pi^{*}$ (C5-C13) and (C7C12) with stabilization energy of 27.44

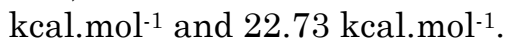

- From LP (3) of Cl14 to $\pi^{*}$ (C8-C9) with stabilization energy of $11.38 \mathrm{kcal} \mathrm{mol}^{-1}$.

- From LP (3) of Cl15 to л* (C7-C12) with stabilization energy of $11.22 \mathrm{kcal}^{\mathrm{mol}}{ }^{-1}$.

- From LP (2) of O17 to $\sigma^{*}$ (N6-H21) and (C16H27) with stabilization energy of 7.32

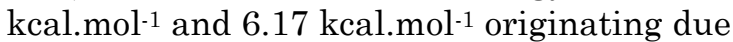
to corresponding delocalized movement of electrons inside the ring. The interaction between donor and acceptor also increases with the increase in value of $\mathrm{E}(2)$.

\subsubsection{Non-linear optical analysis}

The dipole moment of diclofenac sodium is $7.22 \mathrm{D}$ which is much higher than product (i.e. $1.88 \mathrm{D}$ ), while the calculated polarizability and hyper polarizability of diclofenac sodium are $36.37 \times 10^{-24}$ esu and $5.453 \times 10^{-30}$ esu, respec-

Table 5. Calculated thermodynamic parameters of Diclofenac sodium and Oxidation product.

\begin{tabular}{lcc}
\hline Parameters & \multicolumn{2}{c}{ B3LYP/6-31 $\mathrm{G}(\mathrm{d}, \mathrm{p})$} \\
\cline { 1 - 3 } Zolecule & Diclofenac sodium & Oxidation product \\
\hline Rotational Temperature $(\mathrm{K})$ & 132.29731 & 133.22198 \\
& 0.1573 & 0.02531 \\
& 0.00960 & 0.01472 \\
\hline Rotational Constant $(\mathrm{GHz})$ & 0.00793 & 0.01127 \\
$\mathrm{X}$ & & \\
$\mathrm{Y}$ & 0.32769 & 0.52734 \\
$\mathrm{Z}$ & 0.1999 & 0.30669 \\
Total Energy E & 0.16515 & 0.23481 \\
Translational $\left(\mathrm{kcal} . \mathrm{mol}^{-1}\right)$ & 143.902 & 142.641 \\
Rotational & 0.8890 & 0.889 \\
Vibrational & 0.8890 & 0.889 \\
\hline
\end{tabular}

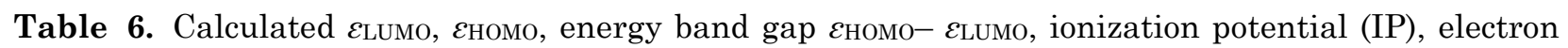
affinity (EA), electronegativity $(x)$, global hardness $(\eta)$, chemical potential $(\mu)$, global electrophilicity index $(\omega)$, global softness $(S)$ and additional electronic charge $\left(\Delta N_{\max }\right)$ in $\mathrm{eV}$ for assayed compounds, using DFT/B3LYP/6-31G(d,p).

\begin{tabular}{lccccccccccc}
\hline $\begin{array}{l}\text { Name of com- } \\
\text { pound }\end{array}$ & $\varepsilon_{\mathrm{H}}$ & $\varepsilon_{\mathrm{L}}$ & $\mathcal{E}_{\mathrm{H}-\mathcal{E}_{\mathrm{L}}}$ & $I P$ & $E A$ & $x$ & $\eta$ & $\mu$ & $\omega$ & $S$ & $\Delta N_{\max }$ \\
\hline $\begin{array}{l}\text { Diclofenac sodi- } \\
\text { um }\end{array}$ & -5.7499 & -0.581 & 5.169 & 5.75 & 0.58 & 3.165 & 2.585 & -3.165 & 1.938 & 0.19 & 1.225 \\
Product & -5.680 & -0.688 & 5.113 & 5.680 & 0.688 & 3.184 & 2.496 & -3.184 & 2.031 & 0.20 & 1.276 \\
\hline
\end{tabular}


tively (Table 4). The values for both diclofenac sodium and its oxidation product were found to be greater than those of urea (the $\beta_{0}$ of urea $\left.0.3728 \times 10^{-30} \mathrm{esu}\right)$. Thus, both are good NLO material.

\subsubsection{Thermodynamic analysis}

Due to the various chemical and physical phenomena thermodynamic analysis play consequential role in elucidation of reaction mechanism. In present analysis, we calculate zero point vibrational energy, rotational constants and various energies, using DFt-B3LYP/6-31G $(\mathrm{d}, \mathrm{p})$ method (Table 5). All the thermodynamic calculations are conducted in gas phase and not in solution.

\subsubsection{Global reactivity descriptors}

The global reactivity descriptors define the type of interaction, bonding and active centre of molecule which helps in elucidation of mechanism. The nature of molecular orbital defines its most reactive position while the HOMOLUMO energy gap defines biological activity of

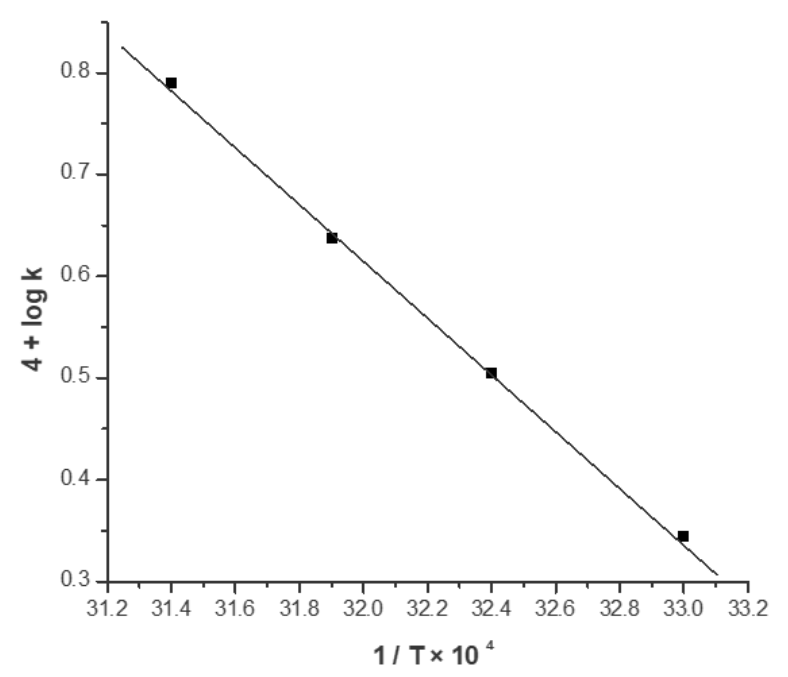

Figure 12. Arrhenius plot between $\log k$ vs. $1 / T$ for oxidation of pharmaceutical drugs (acetylsalicylic acid, acetaminophen and diclofenac sodium). that compound. Least energy gap indicates higher polarizability of molecule and less kinetic stability. Ionization potential (IP), electron affinity $\left(E_{\mathrm{A}}\right)$, electronegativity $(x)$, chemical potential $(\mu)$, global hardness $(\eta)$, global softness $(S)$, and electrophilicity index $(\omega)$ were listed in Table 6. As the HOMO-LUMO energy gap increases, the molecule becomes harder, which resist the deformation of electron cloud. The higher the value of the electrophilicity index $(\omega)$, the better is the electrophilic character. Hence, DFS is less electrophilic than its oxidation product.

\subsection{Thermodynamic Analysis}

A vant Hoff's plot was inclined for the variation of $k$ with temperature [i.e. $\log k$ versus 1/T] (Figure 12) and the values of the enthalpy of reaction $\Delta H$, entropy of reaction $\Delta S$, and free energy of reaction $\Delta G$ were calculated. Moderate $\Delta H^{*}$ and $\Delta E^{*}$ values are favourable for electron transfer reaction. Entropy of activation plays vital role in the chemical reaction between ions or between an ion and a neutral molecule or a neutral molecule forming ions. When reaction takes place between two ions of opposite charges, their union will results in a lowering of net charge, and due this some frozen solvent molecules will released with an increase of entropy. But on the other hand, when reaction takes place between two similarly charged species, the transition state will be a more highly charged ion, and due to this, more solvent molecules will be required for separate the ions, leading to a decrease in entropy. High positive value of free energy change of activation $\left(\Delta G^{*}\right)$ indicated that the transition state was highly solvated, while negative value of entropy of activation $\left(\Delta S^{*}\right)$ suggested the formation of an activated complex with reduction in degree of freedom. Deviation in the rate within the reaction series may be caused by change in the enthalpy or entropy of activation. A negative value of $\Delta S^{*}$ suggests that the two ionic species combine in rate determining step to give a single intermediate complex which is more ordered than the reactants [16-18].

Table 7. Thermodynamic activation parameters for the oxidation of DFS by sodium periodate catalysed by Osmium(VIII) in alkaline medium.

\begin{tabular}{cccc}
\hline Temperature $(\mathrm{K})$ & $k_{1} \times 10^{4}\left(\mathrm{sec}^{-1}\right)$ & $\log A$ & 9.53 \\
\hline 303 & 2.94 & $E \mathrm{a} /(\mathrm{kJ} . \mathrm{mol}-1)$ & 53.22 \\
308 & 4.05 & $\Delta H^{\# /\left(\mathrm{kJ}_{\mathrm{mol}}-1\right)}$ & 50.66 \\
313 & 5.70 & $\Delta S^{\# /\left(J \mathrm{JK}^{-1} \cdot \mathrm{mol}^{-1}\right)}$ & -66.52 \\
315 & 8.20 & $\Delta G^{\# /\left(\mathrm{KJ}^{-1} \mathrm{~mol}-1\right)}$ & 20.54 \\
\hline
\end{tabular}




\subsection{Theory and Discussion of Results}

Ionic strength determination accurately defines $\mathrm{pH}$ of solutions by estimating concentration of all ions in the solution. Similarly in any ionic reaction the interaction between ions play vital role because ions act like conducting spheres for solvent with constant dielectric constant $(\in)$. According to Bohr model for ion in solutions, the force acting between ions,

$$
f=-\frac{Z_{A} Z_{B} e^{2}}{4 \pi \in_{0} \in x^{2}} d x
$$

The negative sign is used because $x$ decreases by $d x$ when ion moves together by a distance $d x$. The work executed for moving ions from its initial state to final $d_{\mathrm{AB}}$ is therefore,

$$
\begin{aligned}
w & =-\int_{\infty}^{d_{A B}} \frac{Z_{A} Z_{B} e^{2}}{4 \pi \in_{0} \in x^{2}} d x \\
& =-\frac{Z_{A} Z_{B} e^{2}}{4 \pi \in_{0} \in d_{A B}}
\end{aligned}
$$

If ions have same sign then work is positive otherwise vice versa. By using Gibbs free energy equation, Equation (4) may be written as,

$$
\ln k=\ln k_{0}-\frac{Z_{A} Z_{B} e^{2}}{4 \pi \epsilon_{0} \in d_{A B} k_{B} T}
$$

The slope of the line obtained by plotting $\ln k$ against $1 / \in$ gives the value of $Z_{A} Z_{B} e^{2} / 4 \pi \epsilon_{o} d_{A B} k_{B} T$. Hence, we can calculate $d_{A B}$ from experimental slope. For elaborating the effect of dielectric constant, we use various

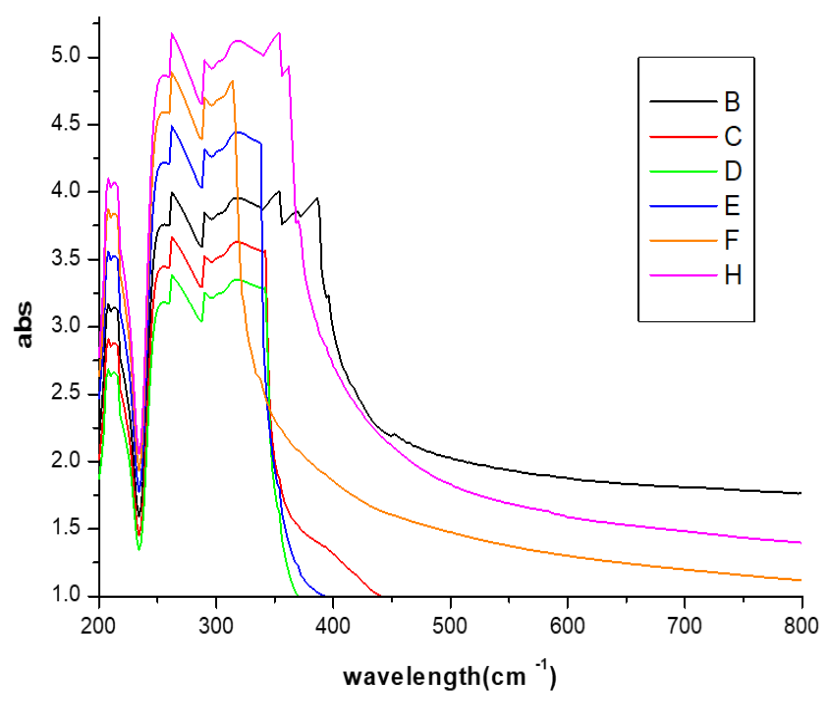

Figure 13. UV spectra showing effect of alkali, oxidant, DFS and catalyst for Os(VIII) catalysed oxidation of DFS by sodium periodate at $35{ }^{\circ} \mathrm{C}$. ratios of Acetic acid and water percentage which alters the dielectric constant of the medium $(D)$. The $D$ values were deliberated from the equation,

$$
D=D_{W} V_{W}+D_{A} V_{A}
$$

where $D_{W}$ and $D_{A}$ are the dielectric constants of pure water and acetic acid respectively and $V_{A}$ and $V_{B}$ are the volume of fractions of components, water and acetic acid, respectively in total mixture. Different reactions were performed with various concentration of acetic acid keeping concentration of all other reactants constant at $35{ }^{\circ} \mathrm{C}$. The concentration of acetic acid varies from $5 \%$ to $20 \%(\mathrm{v} / \mathrm{v})$. The results emphasize that there was no significant effect of dielectric constant under the experimental conditions.

The low value of rate constant for slow step of the mechanism confirms that the oxidation apparently occurs through an inner-sphere mechanism. This conclusion was supported by previous literature [19-20]. The catalyst Os(VIII) forms the complex with organic substrates, which enhances the reducing ability of the substrate than that with no catalyst. Further, the catalyst Os(VIII) modifies the reaction pathway by lowering the energy of activation. The Os(VIII) catalyzed reaction, however, is logically fast in view of speediness of Os(VIII) to act across the $-\mathrm{COO}$ bond. The reaction product does not manipulate the rate in alkaline media since it has been observed that it is not involved in the pre-equilibrium process. All of the observations also confirm the proposed mechanism. On the basis of kinetic results, active species of Os(VIII) oxide and sodium periodate and other kinetic properties with respect to [Substrate], [OH-], [Hg(II)] and ionic strength of medium, the following mechanistic steps are proposed.

\subsection{Reaction Mechanism}

The negative effect of [OH-] indicates that in above reaction equilibrium shifted towards right (Scheme 2). Therefore, the $[\mathrm{OsO} 4(\mathrm{OH}) 2]$ is the active species of osmium(VIII) oxide in alkaline medium.

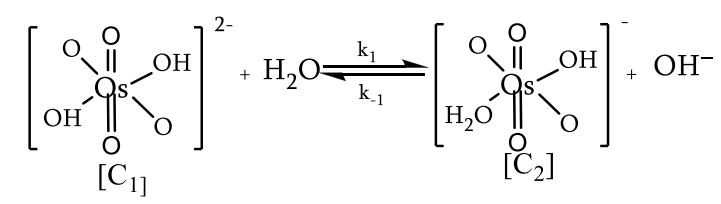

Scheme 2: Hydrolysis of hydrated osmium tetra oxide 
Now in view of above mechanistic steps (Scheme 3), the steady state approximation is applied and following rate law is derived. $\left[\mathrm{Os}(\mathrm{VIII})_{T}\right]$ is equal to sum of concentration of,

$$
\begin{aligned}
& \frac{d\left[\mathrm{IO}_{4}^{-}\right]}{d t}=\text { rate }=k_{3}\left[\mathrm{IO}_{4}^{-}\right][\text {Complex }] \\
& \text { Rate }=\left\{\frac{k_{3} K_{1} K_{2}\left[I O_{4}^{-}\right]\left[O s(V I I)_{T}\right][\text { Drugs }]}{1+K_{1}+\left[\mathrm{OH}^{-}\right]}\right\}
\end{aligned}
$$

The rate law is in agreement with all observed kinetics.

According to mechanism proposed above, Os(VIII) forms complex with drugs. This complex increases the reducing property of substrates and decreases the energy of activation for reaction. The oxygen atom of carboxyl group of the ASA is involved in the formation of intermediate, as the molecular order in ASA. The drugs react with active species of osmium tetra oxide to give a complex, which further reacts with one mole of sodium periodate in rate determining slow step with regeneration of catalyst. Then reaction undergoes a fast step to consume another mole of oxidant, which provides main product of reaction. The probable structure of the complex $\left[\mathrm{C}_{3}\right]$ formed in oxidation reactions are given in Scheme 4.

The spectroscopic evidence for formation of complex between catalyst and substrate was obtained from UV-Vis spectra of drug $\left(1.0 \times 10^{-2}\right.$ mol.dm $\left.{ }^{-3}\right)$, Os(VIII) $\left(2.6 \times 10^{-6} \mathrm{~mol} . \mathrm{dm}^{-3}\right),\left[\mathrm{OH}^{-}\right]$ $\left(1.0 \times 10^{-3} \mathrm{~mol} . \mathrm{dm}^{-3}\right)$ and mixture of both (Figure 13). A hypsochromic shift in between drug and mixture of Os(VIII) was observed.<smiles>O=C([O-])Cc1ccccc1Nc1c(Cl)cccc1Cl</smiles>

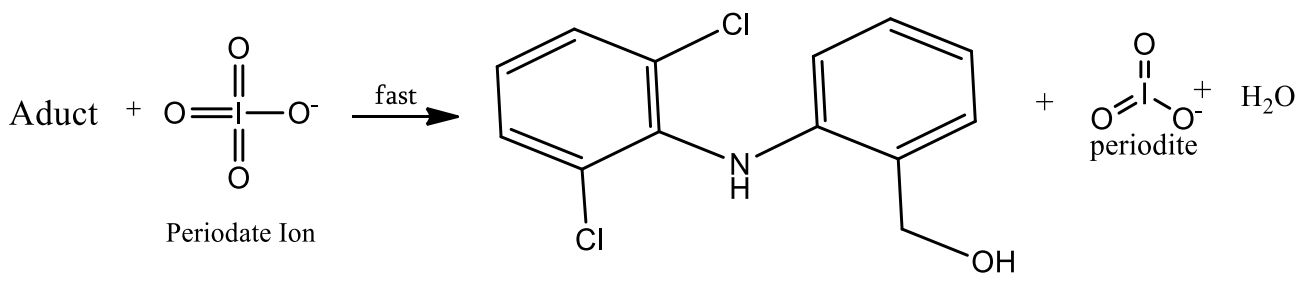

(2-((2,6-dichlorophenyl)amino)phenyl)methanol

Scheme 3. Reaction mechanism of product formation

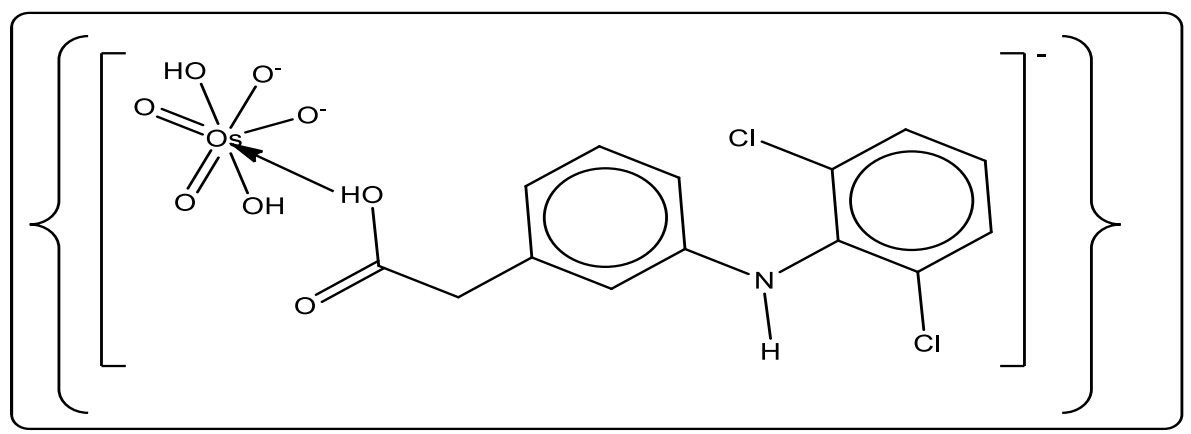

Scheme 4: Structure of complex formed during DFS oxidation 
The Lineweaver-Burk plot proved the complex formation between Os(VIII) and drug, which explains fractional order in [drug]. The rate law for Scheme 1 is derived as,

$$
\begin{aligned}
& \text { Rate }=\frac{d\left[I O_{4}^{-}\right]}{d t} \\
& \text { Rate }=\left\{\frac{k_{3} K_{1} K_{2}\left[I O_{4}^{-}\right]\left[O s(\text { VIII })_{T}\right][\text { Drugs }]}{1+K_{1}+\left[\mathrm{OH}^{-}\right]}\right\} \\
& k=\frac{\text { Rate }}{\left[\text { IO }_{4}^{-}\right]}=\left\{\frac{k_{3} K_{1} K_{2}\left[O s(V I I I)_{T}\right]\left[\text { Drugs }^{-}\right]}{1+\left[\mathrm{OH}^{-}\right]+K_{1}}\right\}
\end{aligned}
$$

The rate law (9) can be rearranged to Equation (10), which is suitable for verification. Equation (10) proves that the plots of $[\mathrm{Os}(\mathrm{VIII})] / k$ vs. $1 /\left[\right.$ drug] and $[\mathrm{Os}(\mathrm{VIII})] / k$ vs. $\left[\mathrm{OH}^{-}\right]$were linear (Figure 14).

$$
\begin{aligned}
\frac{\left[O S(V I I I)_{T}\right]}{k}= & \frac{1}{k_{3} K_{1} K_{2}[\text { Drugs }]}+\frac{\left[\mathrm{OH}^{-}\right]}{k_{3} K_{1} K_{2}[\text { Drugs }]} \\
& +\frac{1}{k_{3} K_{2}[\text { Drugs }]}
\end{aligned}
$$

\section{Conclusion}

The oxidation of DFS by NaIO4 experienced a slow reaction rate in alkaline media, but increased in rate in the existence of the Os(VIII) catalyst. The observed results were explained by plausible mechanisms and the related rate laws were deduced which were further justified by the application of computational approach. The catalyst Os(VIII) forms complex with DFS,

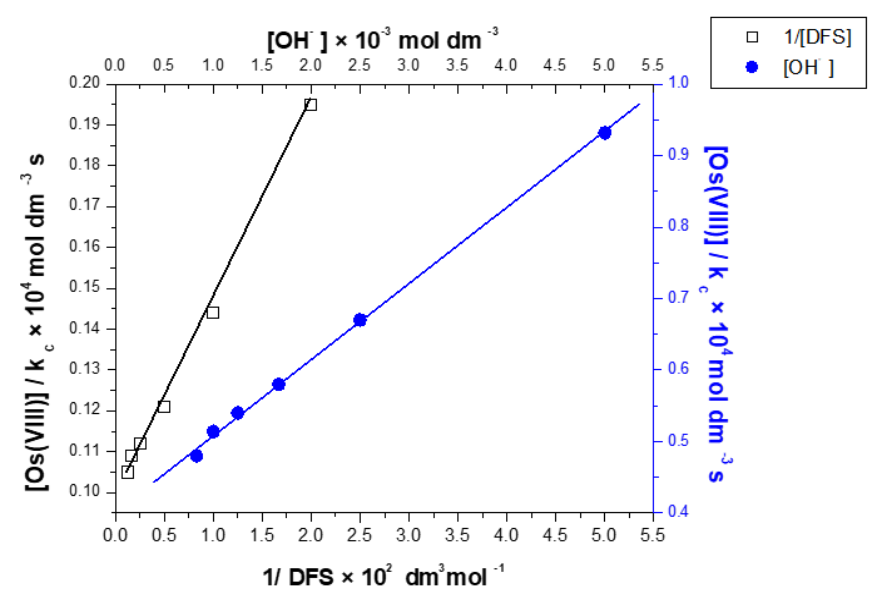

Figure 14. Verification of rate law (2) in form of (3) for Os(VIII) catalyzed oxidation of DFS by sodium periodate at $35^{\circ} \mathrm{C}$. which shows a great reducing property than DFS itself. In the absence of catalyst oxidation of DFS by NaIO4 is very lethargic, but it becomes superficial in the presence of Os(VIII) catalyst. The reactive species of $\mathrm{NaIO}_{4}$ is $\mathrm{IO}_{4}$ not NaIO4 itself. Oxidation products were recognized and activation parameters were evaluated. The observed results have been explained by a reasonable mechanism and the related rate law. The observed results have been explained by mechanism and related law has been deduced. Since the HOMO-LUMO energy gap of product is lower than DFS, so that the product is less stable. On basis of NLO calculations value of $\beta$ o for both DFS and product were higher than urea so both have good optical property. Therefore, we can conclude that both plays vital role in pharmaceutical industry and have NLO applications.

\section{Acknowledgements}

The authors convey their profound thanks to the Head, Department of Chemistry, Lucknow University, Lucknow, for providing laboratory facilities for spectral analysis and central facility for computational research. Authors wish to thank reviewers for greatly improving the paper.

\section{References}

[1] Srivastava, S., Gupta, M. (2015). Osmium(VIII) Catalysed Oxidation of Leucine by Alkaline Sodium Periodate: A Kinetic Study. Bulletin of Catalysis Society of India, 14(1), 15.

[2] Gupta, M., Srivastava, A., Srivastava, S. (2018). Kinetic Mechanistic, and Thermodynamic Studies for Oxidation of L-Alanine by Alkaline Sodium Periodate in Presence of Os(VIII) in its Nano Concentration Range as Homogenous Catalyst. Bulletin of Chemical Reaction Engineering \& Catalysis, 13(2), 355364. DOI: 10.9767/bcrec.13.2.1583.355-364.

[3] Iliescu, T., Baia, M., Miclaus V.A. (2004). A Raman spectroscopic study of the diclofenac sodium-B-cyclodextrin interaction. European Journal Pharmaceutical Science, 22(5), 487495. DOI: 0.1016/j.ejps.2004.05.003.

[4] Gostick, N., James, I.G., Khong, T.K., Roy, P., Shepherd, P.R., Miller, A.J. (1990). Controlled-release indomethacin and sustainedrelease diclofenac sodium in the treatment of osteoarthritis: A comparative controlled clinical trial in general practice. Current Medical Res. Opin., 12(3), 135-142. DOI: $10.1185 / 03007999009111494$ 
[5] Griffith, W. (1967). The Chemistry of Rarer Platinum Metals. Wiley-Interscience Publishers: New York, pp. 141.

[6] Rassolov. V., Ratner, M., Pople, J. (2001). $6-31 \mathrm{G}^{*}$ basis set for third-row atoms. $J$. Comp. Chem., 22, 976-984. DOI: $10.1002 /$ jcc. 1058 .

[7] Hugar, G.H., Nandibewoor, S.T. (1994). Kinetics of osmium(VIII) catalysis of periodate oxidation of DMF in aqueous alkaline medium. Transition Metal Chemistry, 19, 215-217. DOI: 10.1007/BF00161893.

[8] Singh, A., Singh, S.P., Singh, A.K., Singh, B. (2007). Mechanistic study of palladium(II) catalysed oxidationof crotonic acid by periodate in aqueous perchloric acid medium. Journal of Molecular Catalysis A, 266, 226232. DOI: 10.1016/j.molcata.2006.10.046.

[9] Srivastava, A., Gupta, M., Srivastava, S. (2019). Kinetic, Spectroscopic and DFT Studies of Novel Oxidation of Acetylsalicylic Acid by NaIO4 using Micro-amount of Os(VIII) as a Homogeneous Catalyst in Alkaline Medium Russian Journal of Physical Chemistry A, $93(10), \quad 2031-2039 \quad$ D O I : $10.1134 / \mathrm{S} 0036024419100297$.

[10] Gupta, M., Srivastava, A., Srivastava, S. (2019). Comparative Study of Kinetic and Mechanistic Study of Oxidation of L-Alanine and L-Proline by Sodium Periodate Catalyzed by Osmium(VIII) in Micromolar Concentrations, Russian Journal of Physical Chemistry A, $\quad 93(1), \quad 48-58$. D O I : $10.1134 / \mathrm{S} 0036024419010096$.

[11] Farhat, M.F., El-Saghier, A.M.M., Makhlouf, M.A., Kreddan, K.M., Elmezoughi, A.B. (2007). Ketene $N, S$-acetals in heterocyclic synthesis: part 1: synthesis of $N$-phenyl-2ylidene and 2,5-diylidene-4-thiazolidinone derivatives. Journal of Sulfur Chemistry, 28, 563-572. DOI: 10.1080/17415990701586823

[12] Barakat, A., Soliman, S.M., Al-Majid, A.M., Lotfy, G., Ghabbour, H.A., Fun, H.K., Yousuf S., Choudhary, M.I., Wadood, A. (2015). Synthesis and structure investigation of novel pyrimidine-2,4,6-trione derivatives of highly potential biological activity as anti-diabetic agent. Journal of Molecular Structure, 1098, 365-376. DOI: 10.1016/j.molstruc.2015.06.037

[13] Naseem, S., Khalid, M., Tahir, M.N., Halim, M.A., Braga, A.A.C., Naseer, M.M., Shafiq, Z. (2017). Synthesis, structural, DFT studies, docking and antibacterial activity of a xanthene based hydrazone ligand. Journal of Molecular Structure, 1143, 235-244. DOI: 10.1016/j.molstruc.2017.04.093
[14] Sakka, O.K., Fleita, D.H., Harrison, W.T.A. (2013). 2-(4-Oxo-3-phenyl-1,3-thiazolidin- 2ylidene)malononitrile. ActaCrystallogr. E. Struct. Rep. Online, 69, 350. DOI: 10.1107/s160053681300216x

[15] Ahmad, M.S., Khalid, M., Shaheen, M.A., Tahir, M.N., Khan, M.U., Braga, A.A.C., Shad, H.A. (2018). Synthesis and XRD, FT-IR vibrational, UV-vis, and nonlinear optical exploration of novel tetra substituted imidazole derivatives: a synergistic experimentalcomputational analysis. J. Phys. Chem. Sol$i d s, \quad 115, \quad 265-276$. D O I : 10.1016/j.jpcs.2017.12.054

[16] Frisch, Æ., Gaussian 09WReference, Gaussian, Inc., Wallingford, CT, 2009.

[17] Frisch, M.J., Trucks, G.W. et al., Gaussian 09, Revision A.02, Gaussian, Inc., Wallingford CT, 2016.

[18] Tirado-Rives, J., Jorgensen, W. (2008). Performance of B3LYP Density Functional Methods for a Large Set of Organic Molecules. Journal of Chemical Theory Computational, 4, 297-306. DOI: 10.1021/ct700248k.

[19] Caricato, M. (2012). Exploring Potential Energy Surfaces of Electronic Excited States in Solution with the EOM-CCSD-PCM Method. Journal of Chemical Theory Computational, 8, 4494-4502. DOI: 10.1021/ct300382a.

[20] Pyykko, P., Laaksonen, L. (1984). Relativistically parameterized extended Hueckel calculations. 8. Double-.zeta. parameters for the actinoids thorium, protactinium, uranium, neptunium, plutonium, and americium and an application on uranyl. Journal of Physical Chemistry, 88, 4892-4895. DOI: 10.1021/j150665a017.

[21] Sethuram, B. (2003). Some Aspects of Electron Transfer Reactions Involving Organic Molecules, Allied Publishers (P) Ltd., Mumbai, India.

[22] Laidler, J.K. (2004). Chemical Kinetics, 3rd ed.; Pearson Education Ptc. Ltd.: New Delhi, India.

[23] Upadhyay, S.k., Agrawal, M.C. (1977). Kinetics of os(viii)-catalysed alkaline hexacyanoferrate (iii) oxidation of some alpha -amino acids in presence of excess of ferrocyanide. Indian Journal of Chemistry, 15a, 709.

[24] Sutin, N. (1966). The kinetics of inorganic reactions in solution. Annual Review of Physical Chemistry, 17, 119-172.

[25] Lancaster, M., Murray, R.S. (1971). Ferricyanide-Sulphite Reaction, Journal of Chemical Society, A, 2755-2755-2758. DOI: 10.1039/J19710002755 